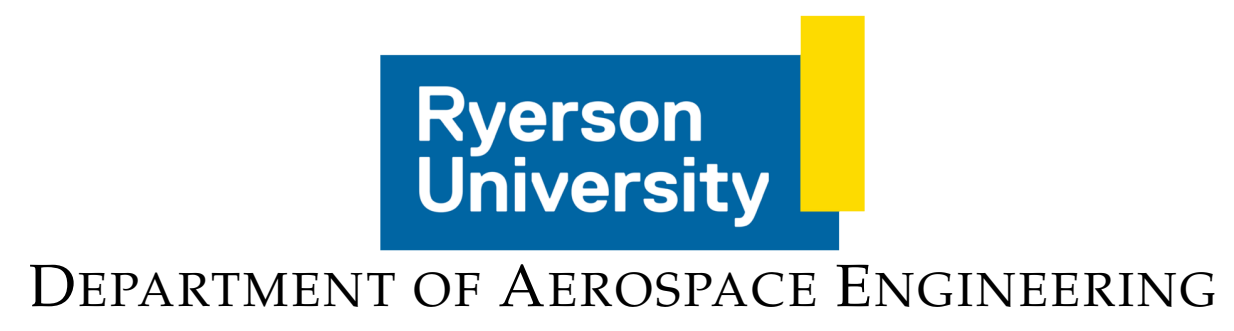

\title{
Simulations of LQR Control on Linear Spacecraft Dynamics about Asteroid Equilibrium Points
}

FINAL REPORT

By:

Abhijeet ARYAL 


\begin{abstract}
Future exploratory missions to asteroids may require a spacecraft to perform attitude and position change maneuvers within small perturbations of the equilibrium point to conduct measurements and make observations based on mission requirements. The non-linear dynamics of the spacecraft can be approximated to be linear given that the system operates about an equilibrium point and the signals are small. Based on this, the linearized system is equivalent to the non-linear system within a limited operating range. This project follows this precedent and applies a closed loop LQR controller to perturbations of $1 \%, 2 \%$ and $5 \%$ from asteroid 101955 Bennu's equilibrium points. The LQR controller methodology requires that weighting matrices $\mathbf{Q}$ and $\mathbf{R}$ which penalize the states and the controls respectively to be iterated for-depending on the application requirements. The iteration procedure is the primary objective of this project and is conducted for six different spacecraft orientations about eight different equilibrium points. The procedure examines the settling times and response plots to critique the performance of the controller. This paper presents the underlying control theory, the modelling scenario, the simulation procedure, results and some patterns discovered in the results. This project was conducted in conjunction with [3] and presents the results of simulations based on linearized spacecraft dynamics. The results of the non-linear spacecraft dynamics simulations can be found in [3].
\end{abstract}




\section{ACKNOWLEDGEMENTS}

The author would like to thank Dr. Anton de Ruiter for the opportunity and guidance throughout the semester. The author would also like to thank Dante A. Bolatti for his regular assistance and guidance with this project. 


\section{TABLE OF CONTENTS}

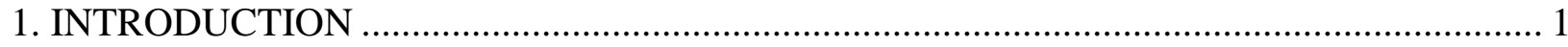

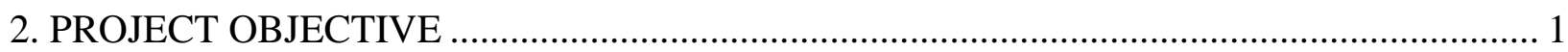

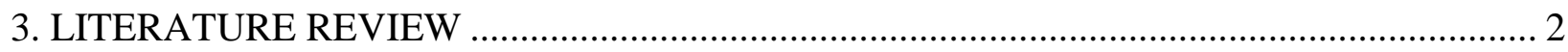

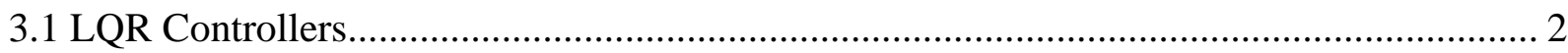

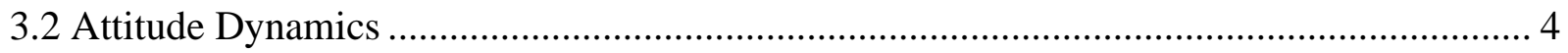

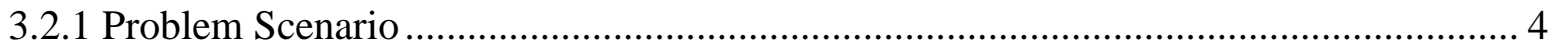

3.2.2 Application to the Controller ................................................................................ 5

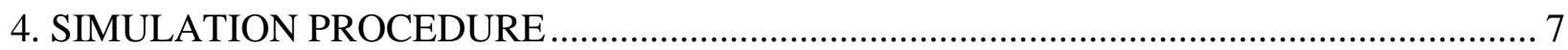

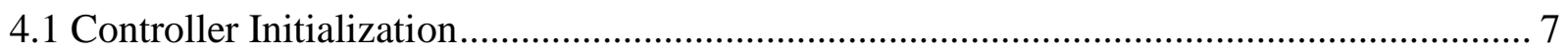

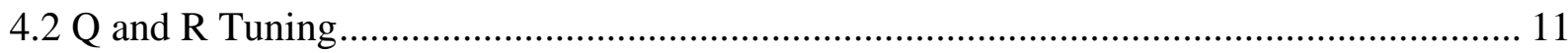

4.3 Simulation Procedure - Summary ………………………………………………...... 13

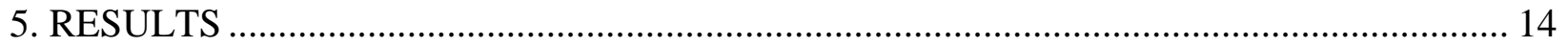

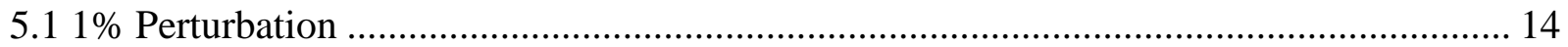

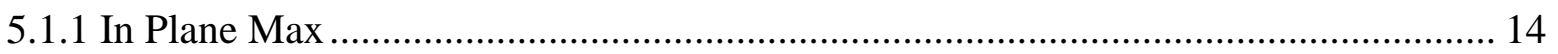

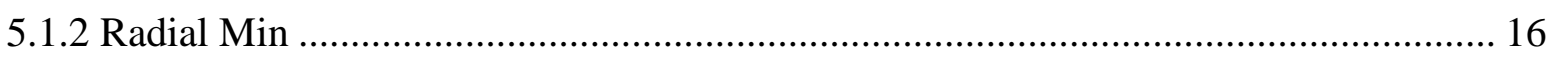

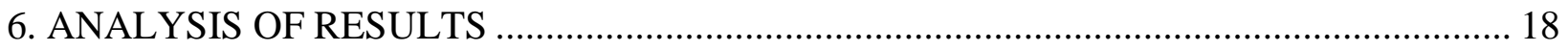

6.1 Proportionality of Q and R..................................................................................... 18

6.2 Common Settling Times for States .......................................................................... 19

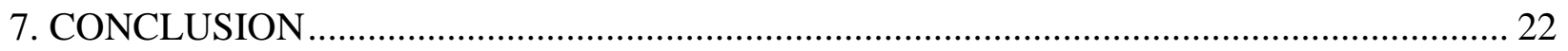

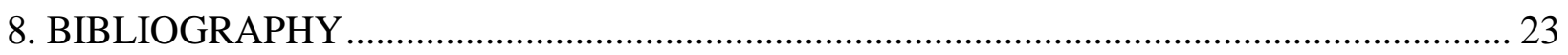

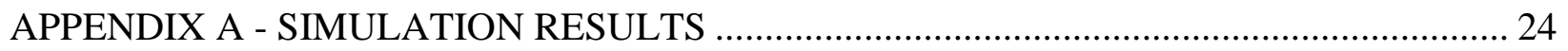

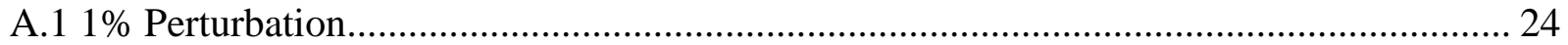

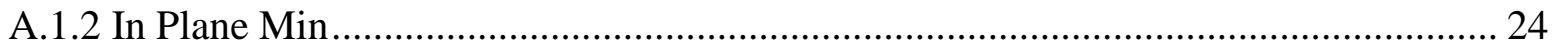

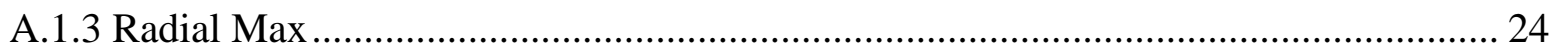

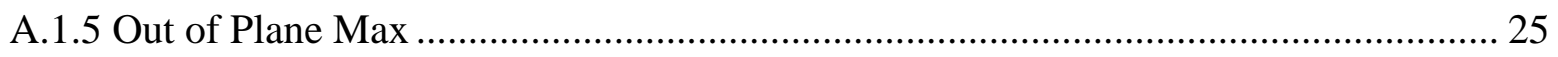

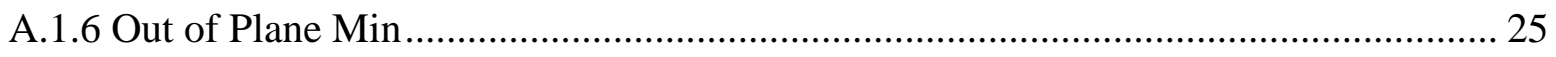

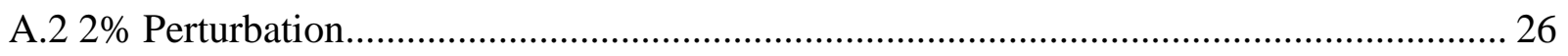

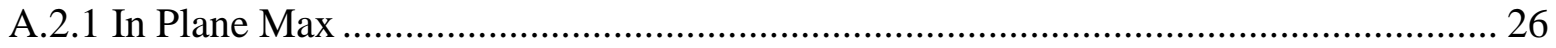

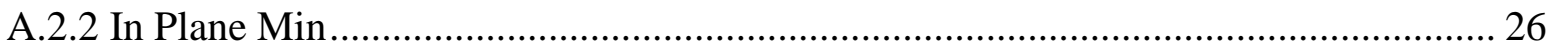



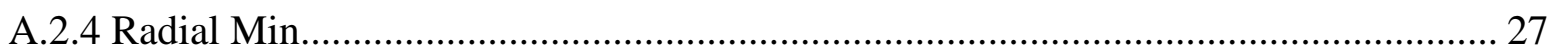




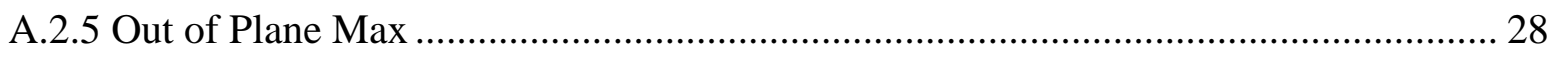

A.2.6 Out of Plane Min ................................................................................................ 28

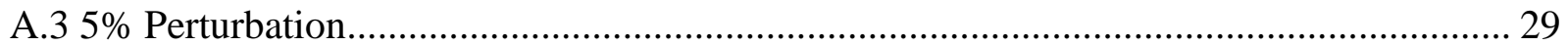

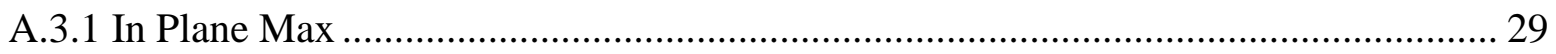

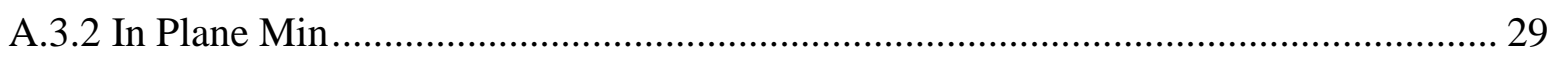

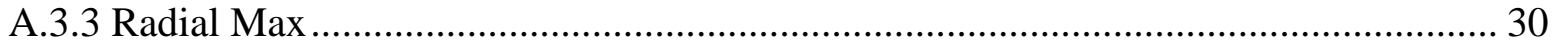

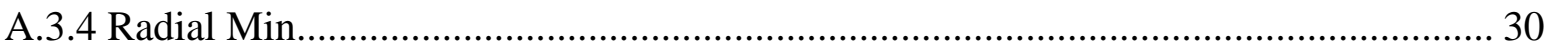

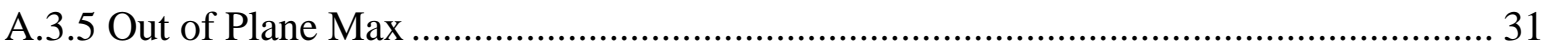

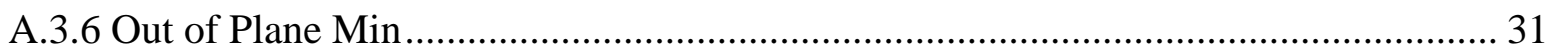

\section{LIST OF FIGURES}

Figure 1: Block Diagram of the Optimal Regulator System [4] ............................................... 2

Figure 2: Equilibrium Points about Bennu [3] ................................................................... 4

Figure 3: Radial Max (L) and Radial Min (R) Orientations [5] ................................................. 4

Figure 4: In Plane Max (L) and In Plane Min (R) Orientations [5] .......................................... 5

Figure 5: Out of Plane Max (L) and Out of Plane Min (R) Orientations [5] ................................. 5

Figure 6: Spacecraft Orientation and Equilibrium Point Specification ......................................... 7

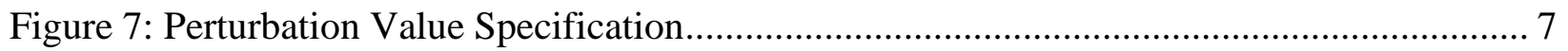

Figure 8: Script Output in the MATLAB workspace …….......................................................... 8

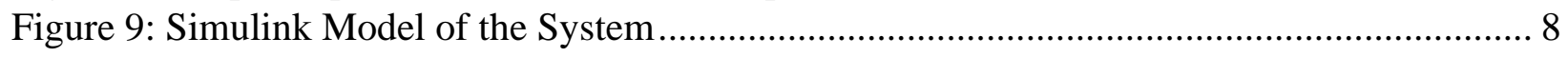

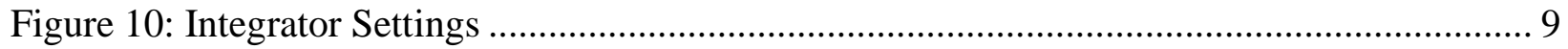

Figure 11: Output States of E1 - In Plane Max ..................................................................... 9

Figure 12: Rates of Spacecraft Motion in E1 - In Plane Max................................................ 9

Figure 13: Control Input Response for E1 - In Plane Max ………......................................... 9

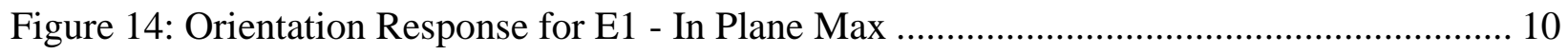

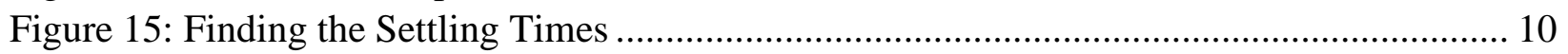

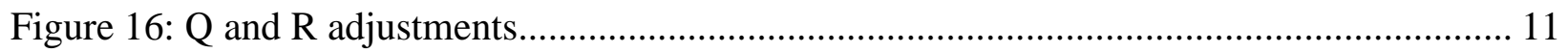

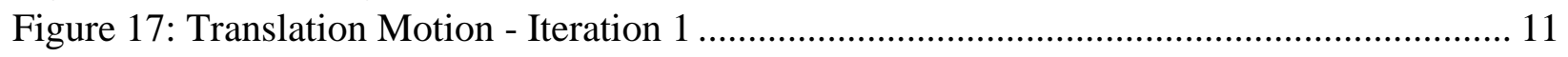

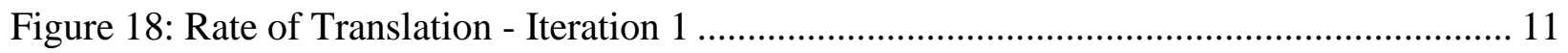

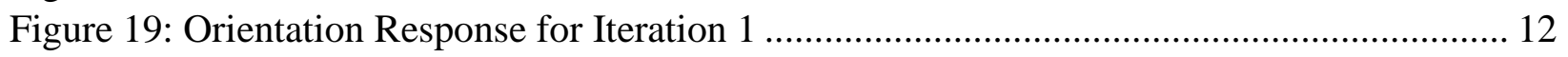

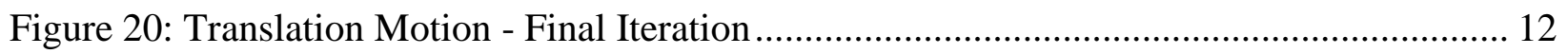

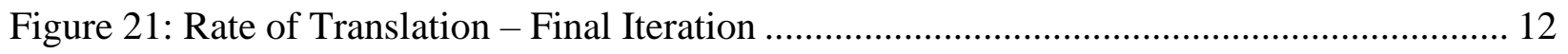

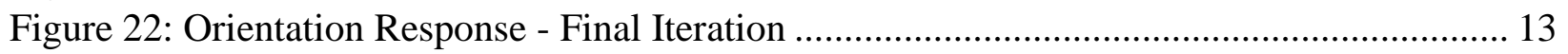

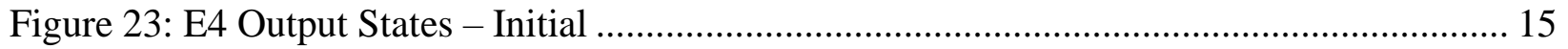

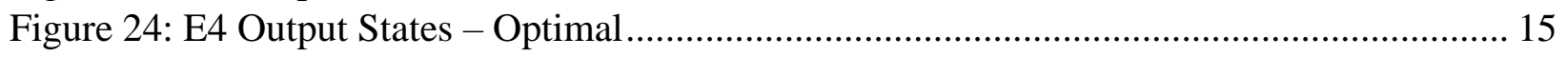

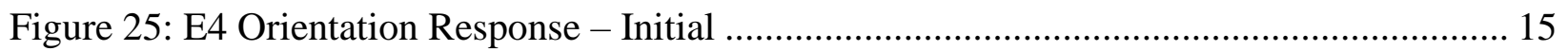

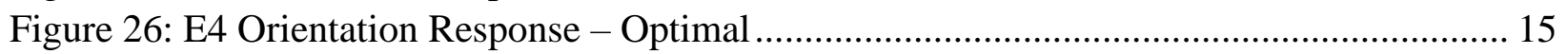

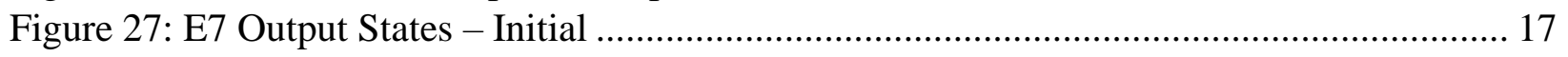

Figure 28: E7 Output States - Optimal.............................................................................. 17 


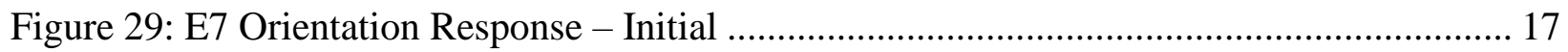

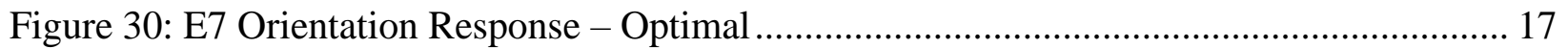

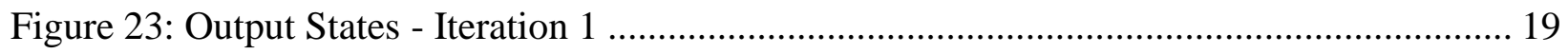

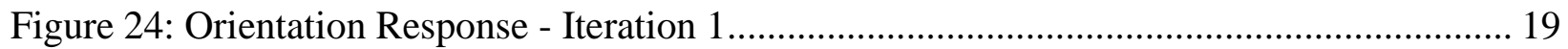

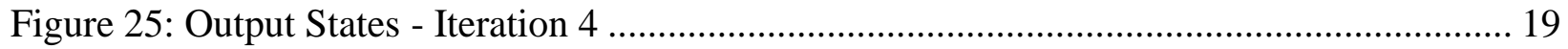

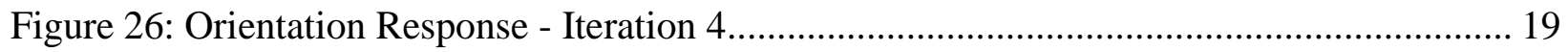

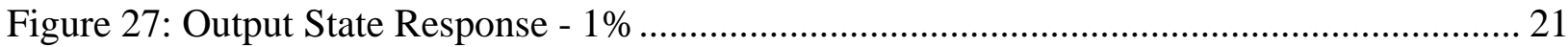

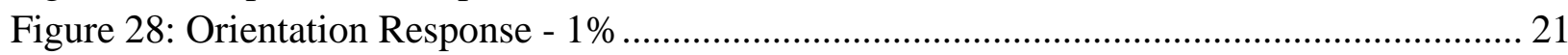

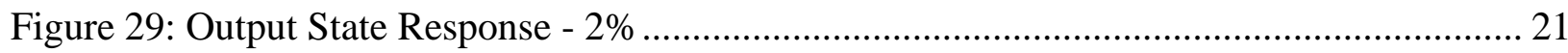

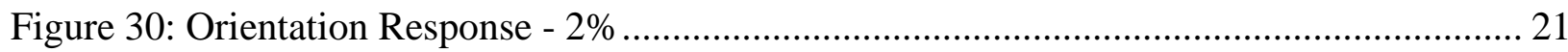

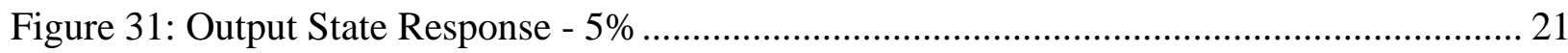

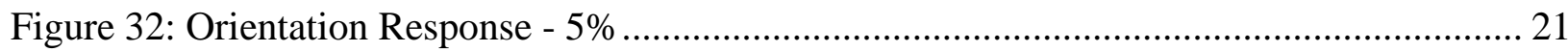

\section{LIST OF TABLES}

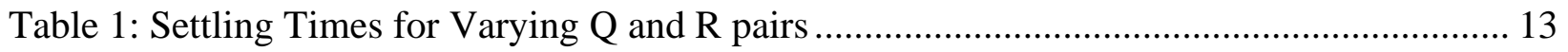

Table 2: Settling Times and Respective Q \& R for each Equilibrium Point at In Plane Max...... 14

Table 3: Settling Times and Respective Q \& R for each Equilibrium Point at Radial Min ......... 16

Table 4: Settling Times for Varying Q and R Pairs ................................................................... 18

Table 5: Settling Times for Varying Perturbations..................................................................... 20

Table 6: Settling Times and Respective Q \& R for each Equilibrium Point at In Plane Min - 1\%

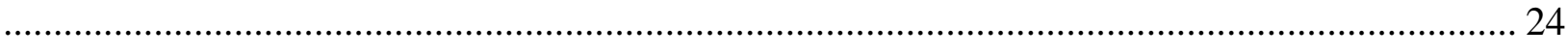

Table 7: Settling Times and Respective Q \& R for each Equilibrium Point at Radial Max - 1\% 24 Table 8: Settling Times and Respective Q \& R for each Equilibrium Point at Out of Plane Max $1 \%$

Table 9: Settling Times and Respective Q \& R for each Equilibrium Point at Out of Plane Min $1 \%$

Table 10: Settling Times and Respective Q \& R for each Equilibrium Point at In Plane Max - 2\%

.

Table 11: Settling Times and Respective Q \& R for each Equilibrium Point at In Plane Min - 2\%

Table 12: Settling Times and Respective Q \& R for each Equilibrium Point at Radial Max - 2\% 27

Table 13: Settling Times and Respective Q \& R for each Equilibrium Point at Radial Min - 2\%

Table 14: Settling Times and Respective Q \& R for each Equilibrium Point at Out of Plane Max $2 \%$

Table 15: Settling Times and Respective Q \& R for each Equilibrium Point at Out of Plane Min $2 \%$

Table 16: Settling Times and Respective Q \& R for each Equilibrium Point at In Plane Max - 5\% 
Table 17: Settling Times and Respective Q \& R for each Equilibrium Point at In Plane Min - 5\%

Table 18: Settling Times and Respective Q \& R for each Equilibrium Point at Radial Max - 5\%

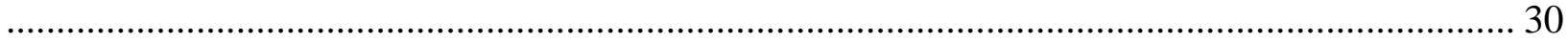

Table 19: Settling Times and Respective Q \& R for each Equilibrium Point at Radial Min - 5\% 30

Table 20: Settling Times and Respective Q \& R for each Equilibrium Point at Out of Plane Max -

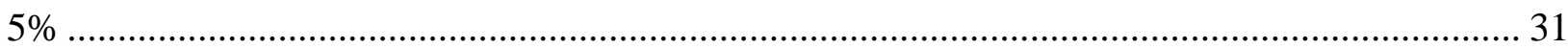

Table 21: Settling Times and Respective Q \& R for each Equilibrium Point at Out of Plane Min -

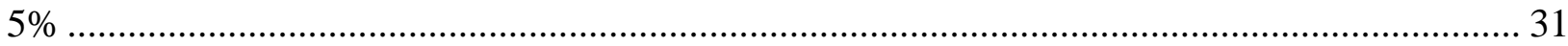




\section{INTRODUCTION}

A growing field of interest in planetary science is the exploration of asteroids for a variety of reasons such as - abundance of metals scarce on Earth, cache of water for future deep space missions, and as they are remnants of the early solar system and can advance the understanding of the formation of Earth along with the origins of life on the planet. However, due to the irregular shape and mass distribution of the asteroid, the weak gravitational field, and the deviations due solar radiation pressure, the orbital and attitude dynamics of the spacecraft close to the asteroid is complicated [1] [2]. Furthermore, exploratory missions to asteroids would require a spacecraft to perform attitude and position change maneuvers within small perturbations of the equilibrium point to conduct measurements and make observations based on mission requirements. In order to satisfy such requirements, this project applies the Linear Quadratic Regulator $(L Q R)$ control method and simulates the performance of the controller based on linearized dynamics of the spacecraft. This paper discusses the underlying control theory, the scenario in which the spacecraft is modelled, the simulation procedure, and the results of the project.

\section{PROJECT OBJECTIVE}

The objective of this thesis project is to tune an LQR controller for stabilization at different equilibrium points about the asteroid 101955 Bennu at varying orientations based on linearized dynamics of a 7x7x50 m spacecraft. The attitude dynamics of the spacecraft along with the details of the controller are already established and this project specifically focuses on the controller design using linearized dynamics. The full details of controller, attitude dynamics and the nonlinearized implementation can be found in [3]. 


\section{LITERATURE REVIEW}

\subsection{LQR Controllers}

The Linear Quadratic Regulator (LQR) controller belongs to the family of Quadratic Optimal Regulator Systems and provides a systematic method of computing the state feedback gain matrix. For a system with the state equation [4]:

$$
\dot{x}=A x+B u
$$

where $\mathbf{A}$ is the state matrix, $\mathbf{x}$ is the state vector, $\mathbf{B}$ is the input matrix and $\mathbf{u}$ is the control input. The performance of a controller on such a system can be judged using the performance index, $\mathbf{J}$, given by [4]:

$$
J=\int_{0}^{\infty}\left(x^{T} Q x+u^{T} R u\right) d t
$$

where $\mathbf{Q}$ is the weighting matrix that penalizes the states and $\mathbf{R}$ is the weighting matrix that penalizes the control. As there is no analytical method to find the values of $\mathbf{Q}$ and $\mathbf{R}$, they must be iterated upon based on the system performance requirements as dictated by the designer.

If the system given by Equation 1 is controllable, an optimal control input vector $\mathbf{u}(\mathbf{t})$ can be found where the performance index $\mathrm{J}$ is minimized. The optimal control input vector is proportional to the optimal gain $\mathrm{K}$ and the relationship is the Optimal Control Law given by [4]:

$$
\boldsymbol{u}(\boldsymbol{t})=-\boldsymbol{K} \boldsymbol{x}(\boldsymbol{t})
$$

If the elements of the matrix $\mathbf{K}$ is found which minimizes the performance index, $\mathbf{J}$, then the control input matrix given by Equation 3 is optimal for any initial state $\mathbf{x}(\mathbf{t})$. Note that although the system that minimizes the performance index is called optimal, in practice the system may not necessarily provide an "optimal" configuration. However, a system designed based on the quadratic performance index does ensure that the design yields a stable control system [4]. The optimal configuration of the system is shown below in Figure 1.

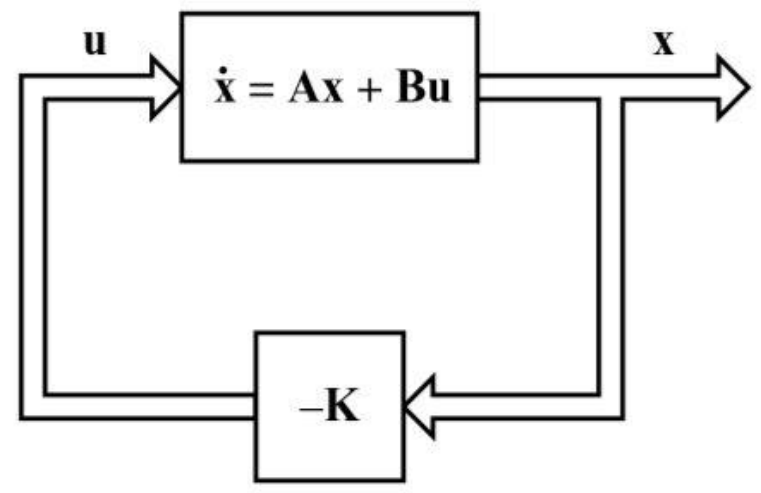

Figure 1: Block Diagram of the Optimal Regulator System [4] 
To optimize the performance of the controller, the optimal gain matrix $\mathbf{K}$ must be found relative to the system state, $\dot{\boldsymbol{x}}=\boldsymbol{A} \boldsymbol{x}+\boldsymbol{B u}$. Following a series of derivations beyond the scope of this project, the optimal gain matrix, $\mathbf{K}$, can be found by [4]:

$$
K=R^{-1} B^{T} P
$$

where $\mathbf{P}$ is a positive-definite matrix. To find the optimal gain in Equation 4, the elements of $\mathbf{P}$ must be first found using the Reduced Matrix Ricatti Equation given by [4]:

$$
A^{T} P+P A-P B R^{-1} B^{T} P+Q=0
$$

In summary, the design procedure is as follows:

1. Determine the state matrix $\mathbf{A}$, and the input matrix $\mathbf{B}$ based on the system dynamics.

2. Iterate to find the values of the state weights, $\mathbf{Q}$ and the input weights $\mathbf{R}$ based on the desired system performance.

3. Solve the Reduced-Matrix Ricatti Equation (Equation 5) for the matrix $\mathbf{P}$.

4. Substitute the matrix $\mathbf{P}$ into the optimal gain matrix $\mathbf{K}$ expression in Equation 4. The result is the optimal matrix $\mathbf{K}$ used to find the optimal control input vector $\boldsymbol{u}(\boldsymbol{t})=-\boldsymbol{K} \boldsymbol{x}(\boldsymbol{t})$.

Steps 3 and 4 can be simulated in MATLAB by using the command: $[K, P, E]=\operatorname{lgr}(A, B, Q, R)$ - which returns the gain value $\mathbf{K}$, the solution to the Riccatti's equation $\mathbf{P}$, and the eigenvalue vector $\mathbf{E}$. 


\subsection{Attitude Dynamics}

\subsubsection{Problem Scenario}

This project applies the LQR controller method to the attitude stabilization of a spacecraft about the asteroid 101955 Bennu around its eight equilibrium points (E1, E2, E3, E4, E5, E6, E7, E8) as shown in Figure 2.

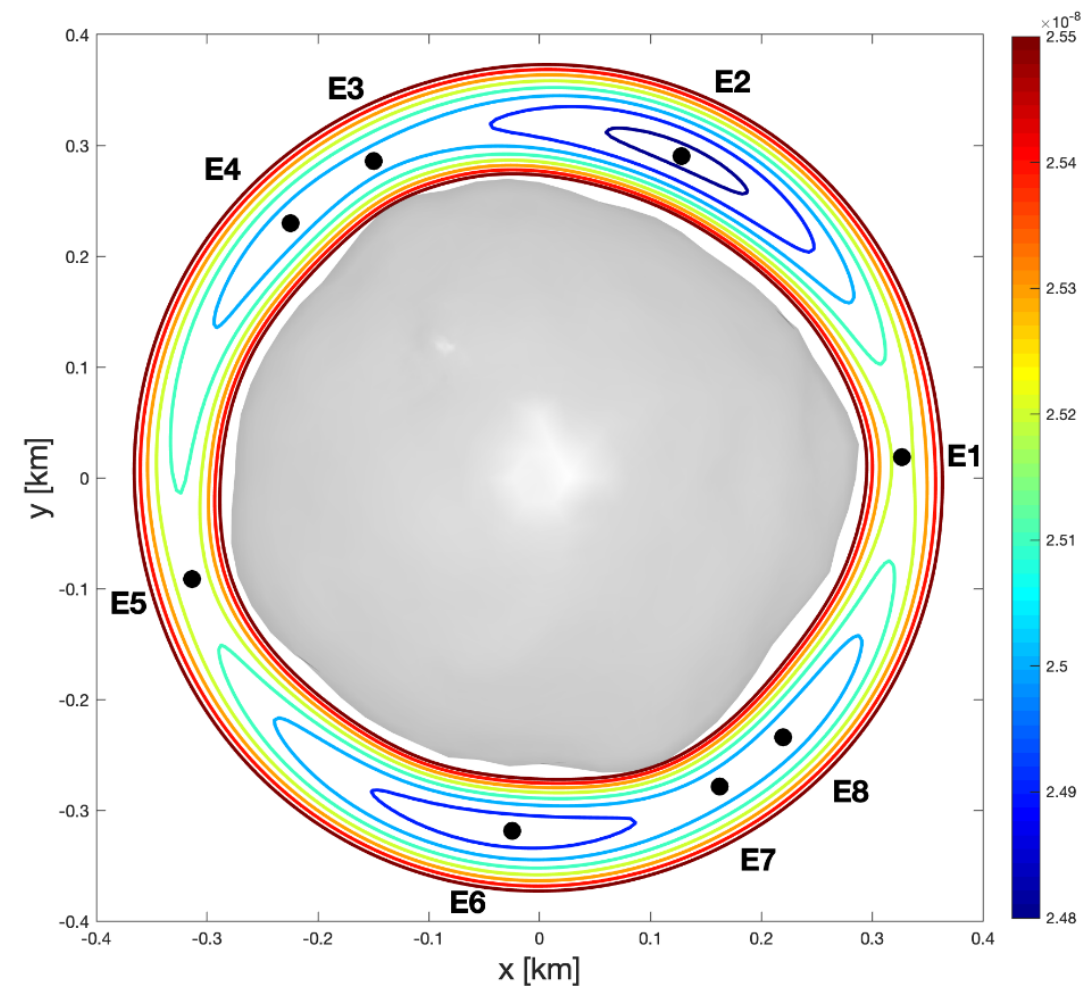

Figure 2: Equilibrium Points about Bennu [3]

About the eight equilibrium points, the spacecraft can also be placed in six different orientations, Radial Max, Radial Min, In Plane Max, In Plane Min, Out of Plane Max and Out of Plane Min as shown in Figure 3, Figure 4 and Figure 5 respectively.
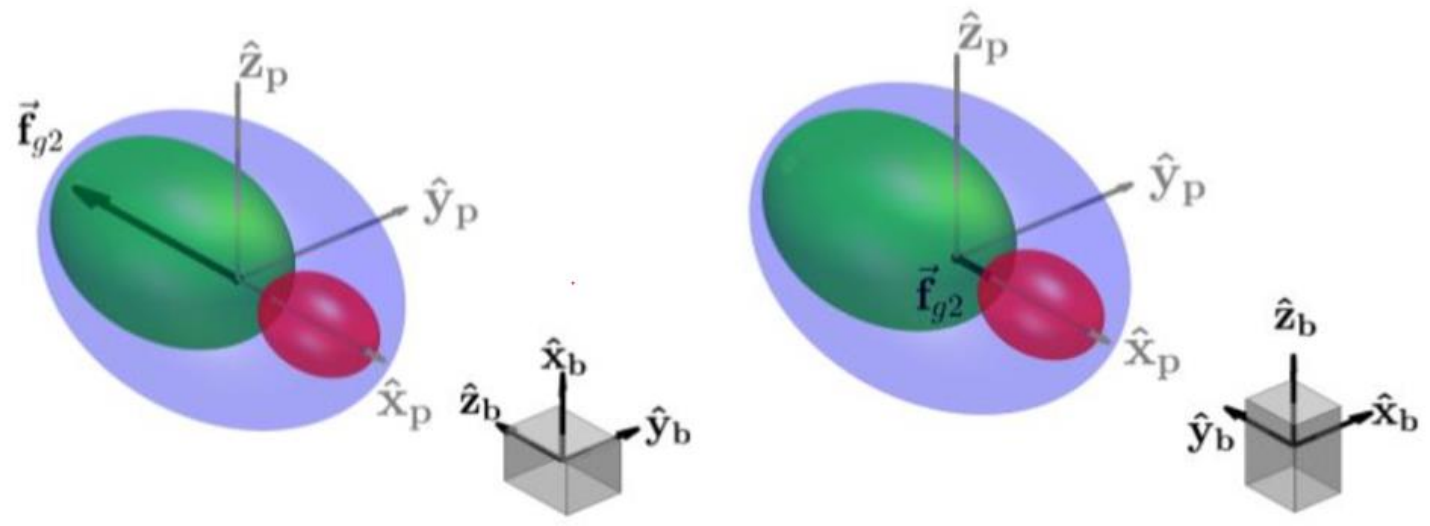

Figure 3: Radial Max (L) and Radial Min (R) Orientations [5] 

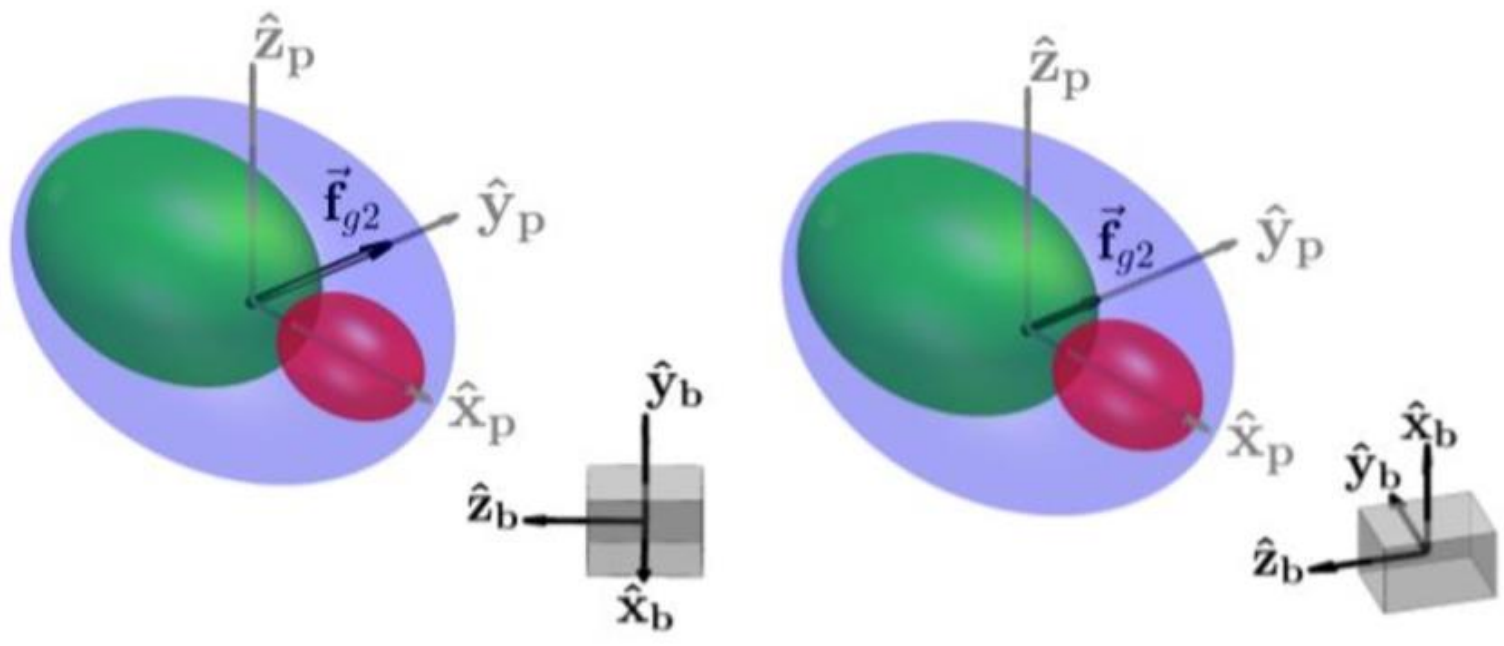

Figure 4: In Plane Max (L) and In Plane Min (R) Orientations [5]
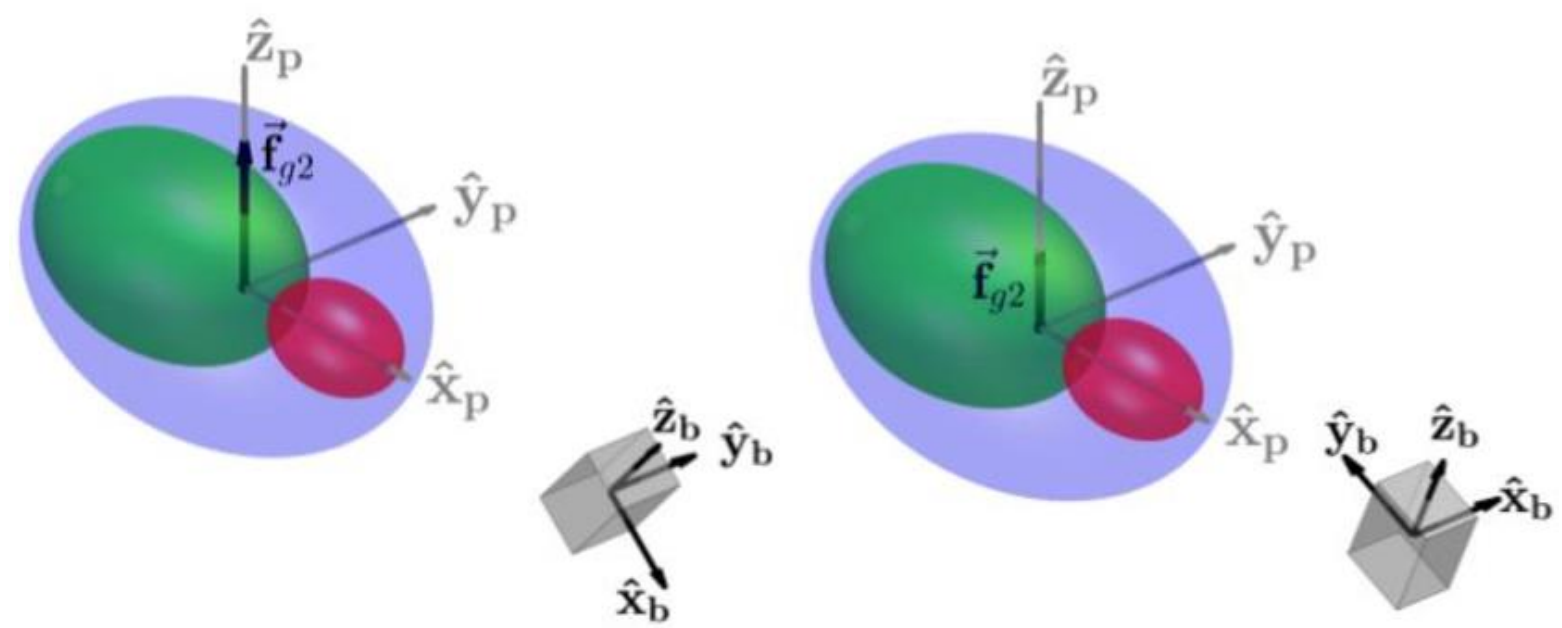

Figure 5: Out of Plane Max (L) and Out of Plane Min (R) Orientations [5]

The combination of eight equilibrium points about the asteroid along with the six different orientations of the spacecraft means that there are 48 possible configurations.

\subsubsection{Application to the Controller}

Now with the problem scenario defined, the state vector $\mathbf{x}$ given as [5]:

$$
\boldsymbol{x}=\left[\begin{array}{c}
\phi \\
\theta \\
\psi \\
\dot{\phi} \\
\dot{\theta} \\
\dot{\psi}
\end{array}\right]
$$


Where $(\phi, \theta, \psi)$ and $(\dot{\phi}, \dot{\theta}, \dot{\psi})$ are the Euler rotation angles (roll, pitch and yaw) and the angular rates of the spacecraft body frame $\mathcal{F}_{b}$ relative to the asteroid body frame $\mathcal{F}_{o}$. The control input vector $\mathbf{u}$ is defined as [5]:

$$
\boldsymbol{u}=\left[\begin{array}{l}
T_{x_{c}} \\
T_{y_{c}} \\
T_{z_{c}}
\end{array}\right]
$$

where $\left(T_{x_{c}}, T_{y_{c}}, T_{z_{c}}\right)$ are the control torques applied to the spacecraft. Then, the attitude dynamics of the spacecraft can be defined using the state matrix $\mathbf{A}$ and the input matrix $\mathbf{B}$ as [5]:

$$
\boldsymbol{A}=\left[\begin{array}{cccccc}
0 & 0 & 0 & 0 & 0 & 0 \\
0 & 0 & 0 & 0 & 1 & 0 \\
0 & 0 & 0 & 0 & 0 & 1 \\
\frac{4 \omega_{o}^{2}}{I_{x}}\left(I_{z}-I_{y}\right) & 0 & 0 & 0 & 0 & \frac{\omega_{o}}{I_{x}}\left(I_{x}-I_{y}+I_{z}\right) \\
0 & \frac{3 \omega_{o}^{2}}{T_{y}}\left(I_{z}-I_{y}\right) & 0 & 0 & 0 & 0 \\
0 & 0 & \frac{\omega_{o}^{2}}{I_{z}}\left(I_{x}-I_{y}\right) & \frac{\omega_{o}}{I_{z}}\left(I_{y}-I_{x}-I_{z}\right) & 0 & 0
\end{array}\right]
$$

$$
\boldsymbol{B}=\left[\begin{array}{ccc}
0 & 0 & 0 \\
0 & 0 & 0 \\
0 & 0 & 0 \\
\frac{1}{I_{x}} & 0 & 0 \\
0 & \frac{1}{I_{y}} & 0 \\
0 & 0 & \frac{1}{I_{z}}
\end{array}\right]
$$

where $\left(I_{x}, I_{y}, I_{z}\right)$ are the spacecraft's principal moments of inertia, and $\omega_{o}$ is the orbital angular rate. From the matrices of $\mathbf{A}$ and $\mathbf{B}$, the state-space model of the spacecraft can be defined using Equation 1.

The non-linear dynamics of the spacecraft can then be approximated to be linear given that the system operates about an equilibrium point and the signals are small. From this, the linearized system is equivalent to the non-linear system within a limited operating range. This project follows this precedent and applies the controller to perturbations of $1 \%, 2 \%$ and $5 \%$, while the full linearization procedure and the results of the non-linear dynamics simulations can be found in [3]. 


\section{SIMULATION PROCEDURE}

The primary objective of the simulation procedure is to adjust the $\mathbf{Q}$ and $\mathbf{R}$ matrices. As discussed in Section 3.1, the $\mathbf{Q}$ and $\mathbf{R}$ pairs are applied to the performance index, J, from which an optimal control input $\mathbf{u}(\mathbf{t})$ can be found. Thus, it must be considered that the control input needs to be small enough to avoid spinning the spacecraft uncontrollably, but also high enough to return to the equilibrium point in a reasonable amount of time. As discussed in Section 3.1, there is no analytical procedure for finding $\mathbf{Q}$ and $\mathbf{R}$ and thus these values must be iterated upon for each of the 48 different configurations. The full MATLAB script for the simulation, LQR_controller_initialization.m, LQR_Q_and_R_initialization.m, figures.m scripts and the Simulink model system_block_diagram_closed_loop_LQR.slx, can be found in [3] and the procedure depicted in this section demonstrates that used for equilibrium point $\mathrm{E} 1$ in the In Plane Max orientation at $1 \%$ perturbation.

\subsection{Controller Initialization}

First the controller must be initialized about the asteroid equilibrium point and the procedure is as follows:

1. The asteroid and spacecraft data is loaded onto the MATLAB workspace.

2. In the LQR_controller_initialization.m script, the spacecraft orientation and the equilibrium points can be specified in Lines 21 and 29 respectively as shown in Figure 6.

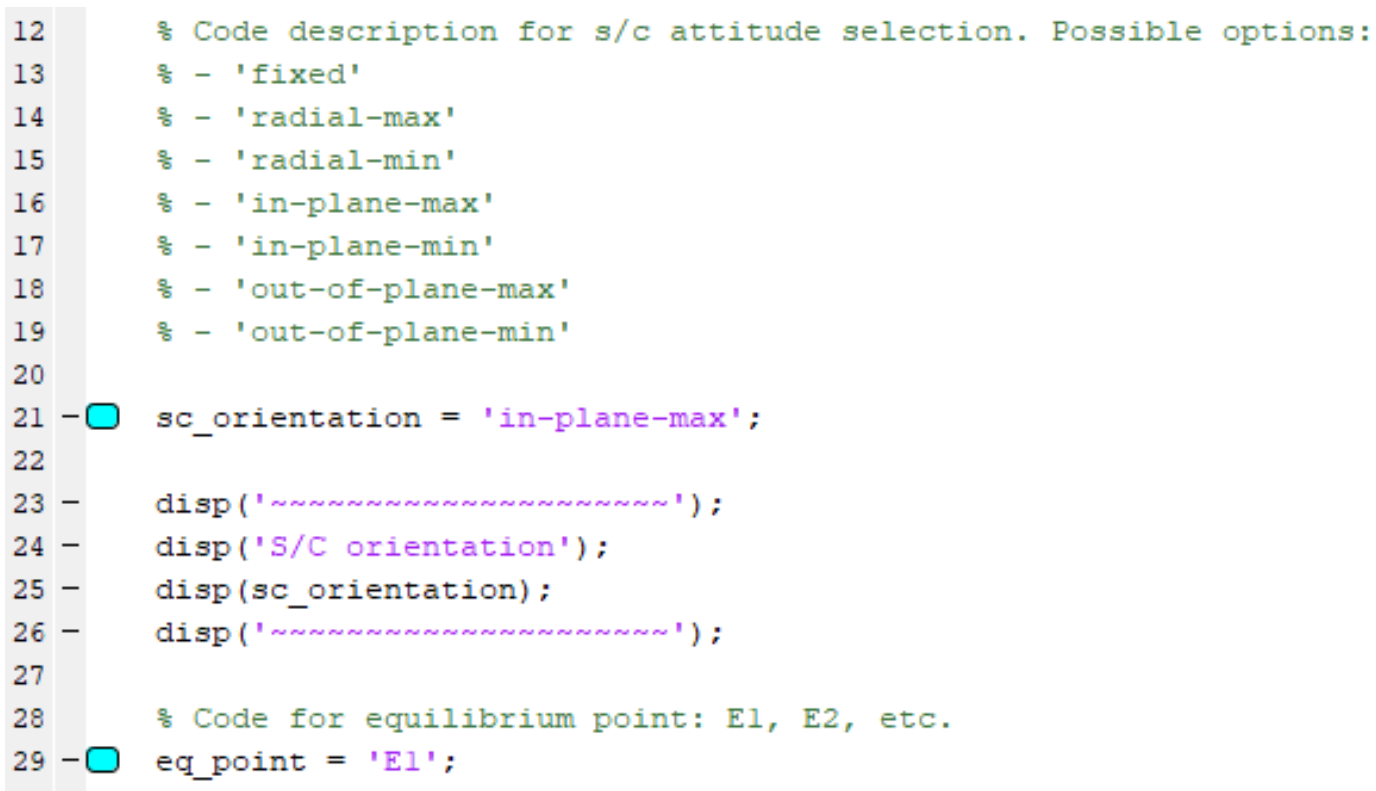

Figure 6: Spacecraft Orientation and Equilibrium Point Specification

3. The perturbation value can also be specified in Line 53 as shown in Figure 7.

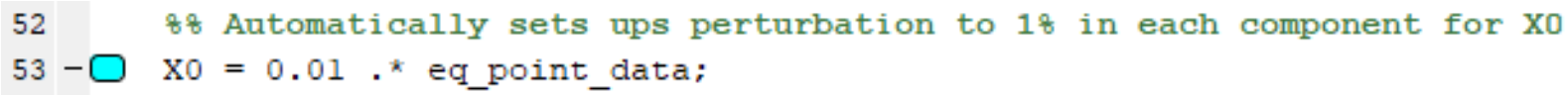

Figure 7: Perturbation Value Specification 
4. The initial $\mathbf{Q}$ and $\mathbf{R}$ pairs are also specified in the script as a $6 \times 6$ and $3 \times 3$ identity matrices, respectively. The identity matrices are then multiplied by $1 E 10$ and $1 E 6$ for $\mathbf{Q}$ and $\mathbf{R}$, respectively. This value pair was chosen arbitrarily and is used the initialization of all 48 configurations.

5. Then the script is run, and the equilibrium point along with the associated perturbation can be seen in the workspace as shown in Figure 8.

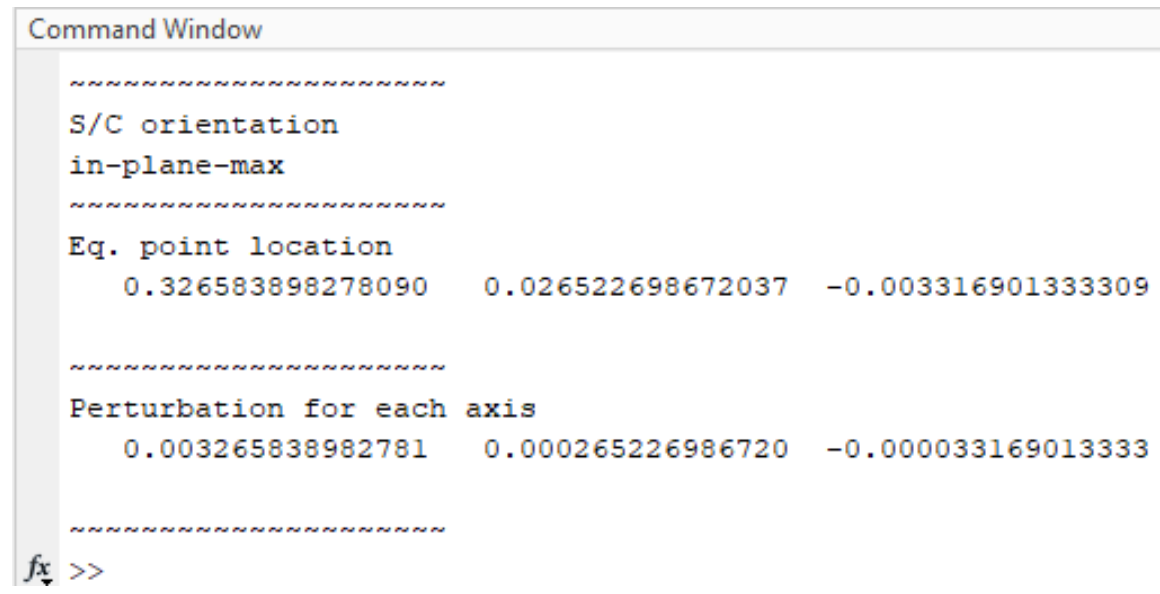

Figure 8: Script Output in the MATLAB workspace

6. Now the Simulink model as shown in Figure 9 is run with the integrator set as ode4 and with a 1 second time step as depicted in Figure 10.

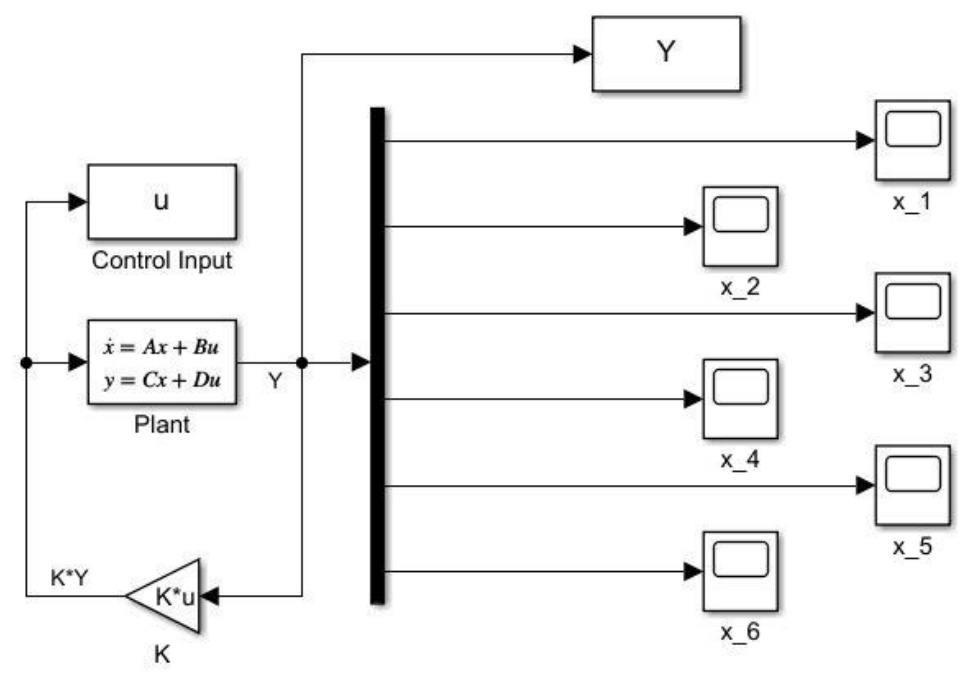

Figure 9: Simulink Model of the System 


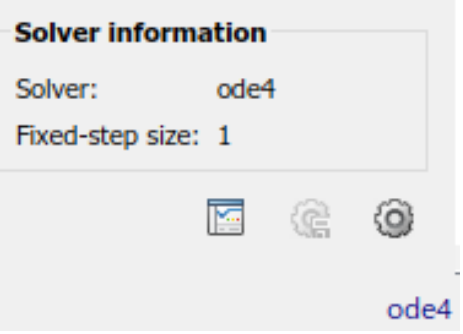

Figure 10: Integrator Settings

7. Now executing the figures.m script outputs three response plots - Output States, Control Input ' $u$ ' and Orientation Response as shown in Figure 11, 12 and 13, respectively.

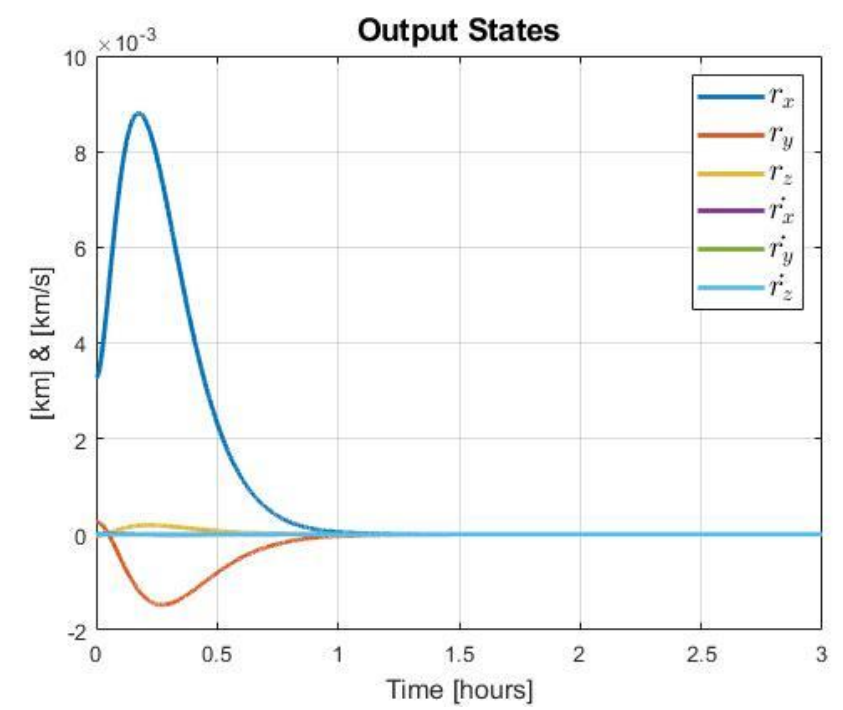

Figure 11: Output States of E1 - In Plane Max

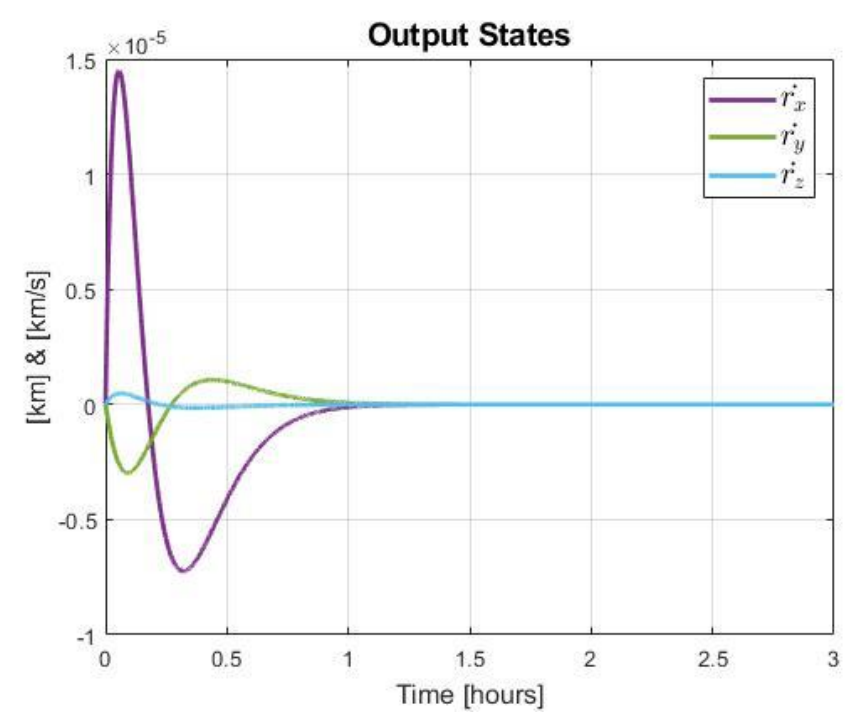

Figure 12: Rates of Spacecraft Motion in E1 - In Plane Max

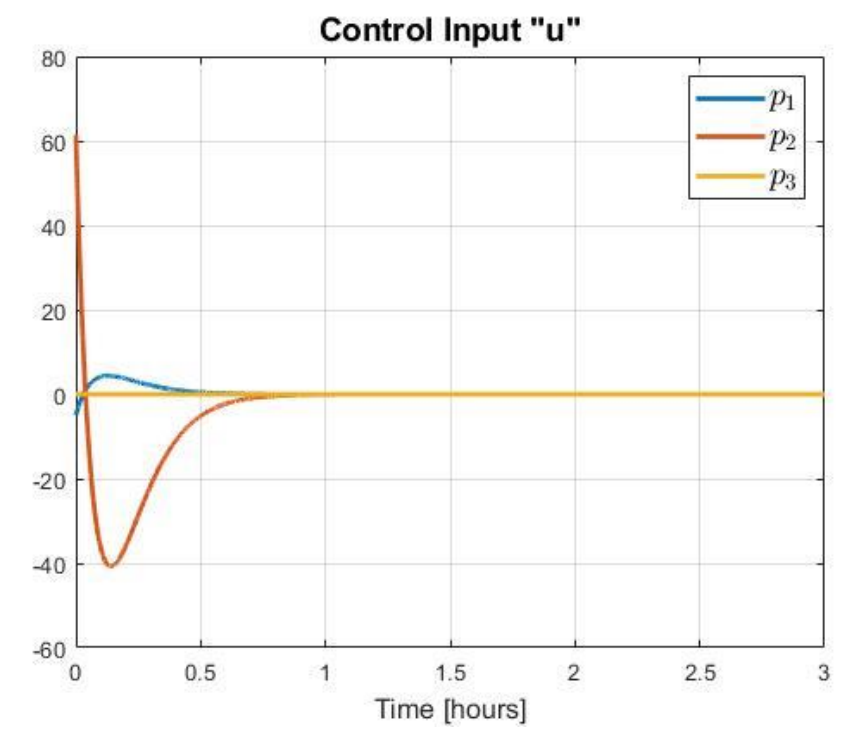

Figure 13: Control Input Response for E1 - In Plane Max 


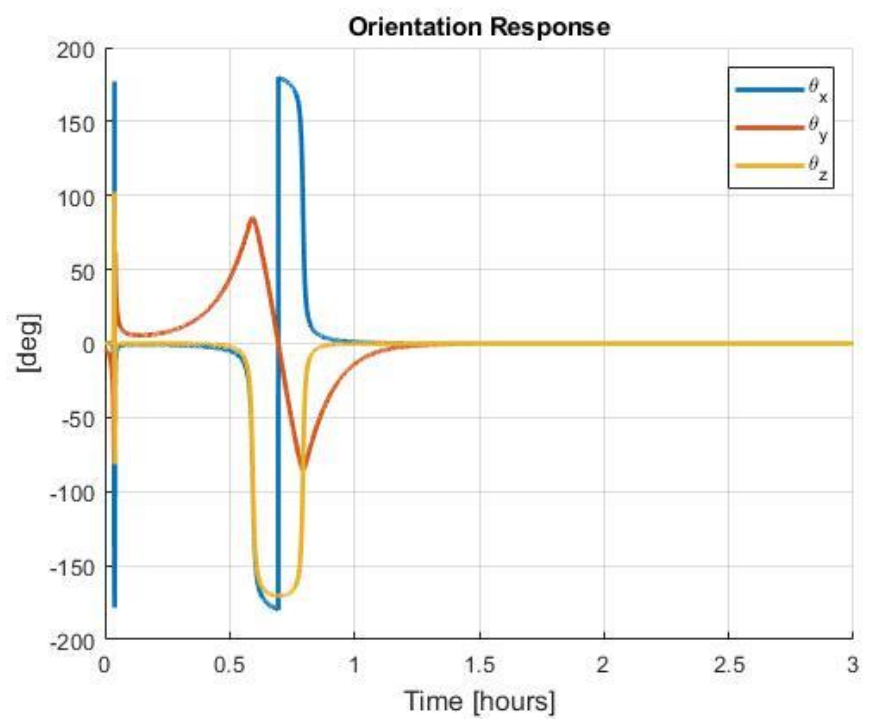

Figure 14: Orientation Response for E1 - In Plane Max

8. The Output States response shows the translational motion of the spacecraft following a perturbation with its position with respect to time shown in Figure 11 and the rate of motion shown in Figure 12. The Control Input " $u$ " response in Figure 13 shows the spacecraft orientations in Modified Rodrigues Parameters (MRP). Transforming the MRP control input into Euler angles gives the Orientation Response plot in Figure 14. Since the MRP is beyond the scope of the project, the Output States and Orientation Response plots will be primarily examined throughout the project. These plots must all converge to the $y=0$, representing that the spacecraft has returned to the equilibrium point and is no longer in any motion - translational or rotational.

9. Using the values of $\boldsymbol{Y}$ and $\left(\boldsymbol{r}_{\boldsymbol{x}}, \boldsymbol{r}_{\boldsymbol{y}}, \boldsymbol{r}_{\boldsymbol{z}}\right)$ used to plot the Output States plot and the Orientation Response plot respectively, the settling time of the responses can also be calculated using the MATLAB commands stepinfo() as shown in Figure 15.

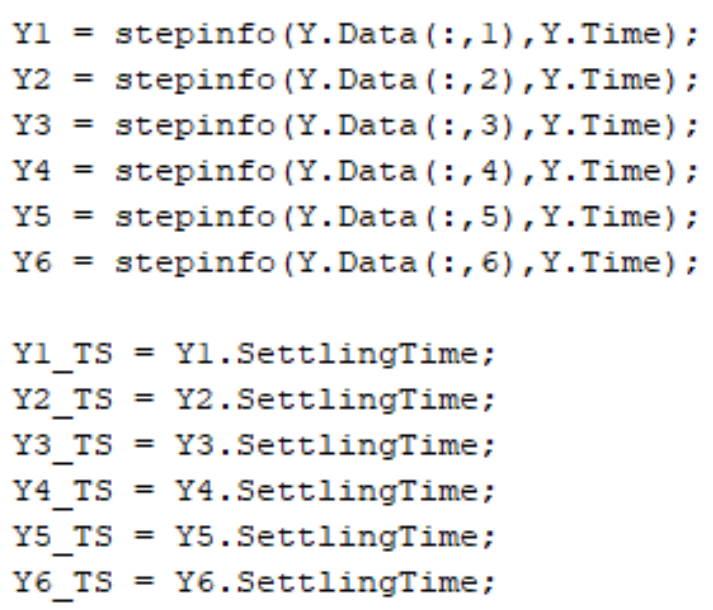

Figure 15: Finding the Settling Times 
The settling time is the primary parameter used to judge the performance of the controller and the settling times found from the initialized system will then be compared to that found from the iterated $\mathbf{Q}$ and $\mathbf{R}$ as shown below in Section 4.2.

\section{2 $Q$ and $R$ Tuning}

With the settling time responses found in Section 4.1, the $\mathbf{Q}$ and $\mathbf{R}$ pairs can be iterated upon using the LQR_Q_and_R_initialization.m script.

1. With the asteroid and spacecraft data already loaded onto the workspace, the values of $\mathbf{Q}$ and $\mathbf{R}$ can be iterated from Line 6 and 7 respectively as shown in Figure 16.

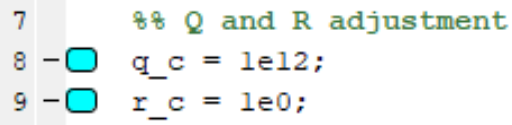

Figure 16: $Q$ and $R$ adjustments

2. As the controller is applied to spacecraft mission where the amount of available fuel and thus control torque is limited, the $\mathbf{R}$ is kept to a value of 1 and $\mathbf{Q}$ is iterated upon. The first iteration value of $\mathbf{Q}$ is randomly selected and iterated upon with the objective of minimizing the settling times.

3. Starting with a value of $\mathbf{Q}=1 \mathrm{E} 12$ and running the Simulink model and the figures.m script the following response plots are returned:

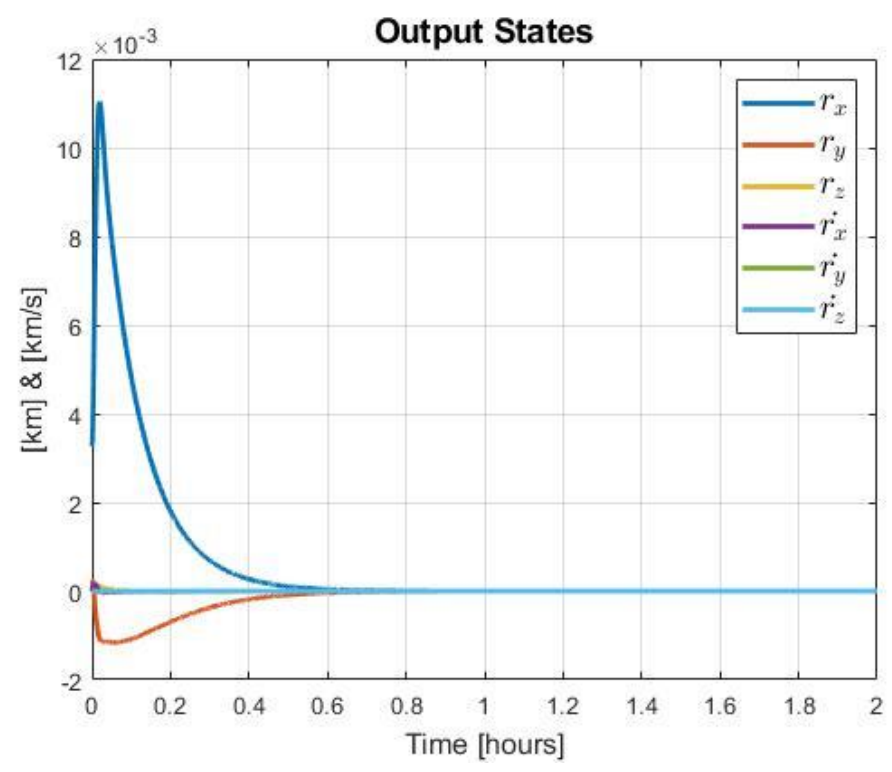

Figure 17: Translation Motion - Iteration 1

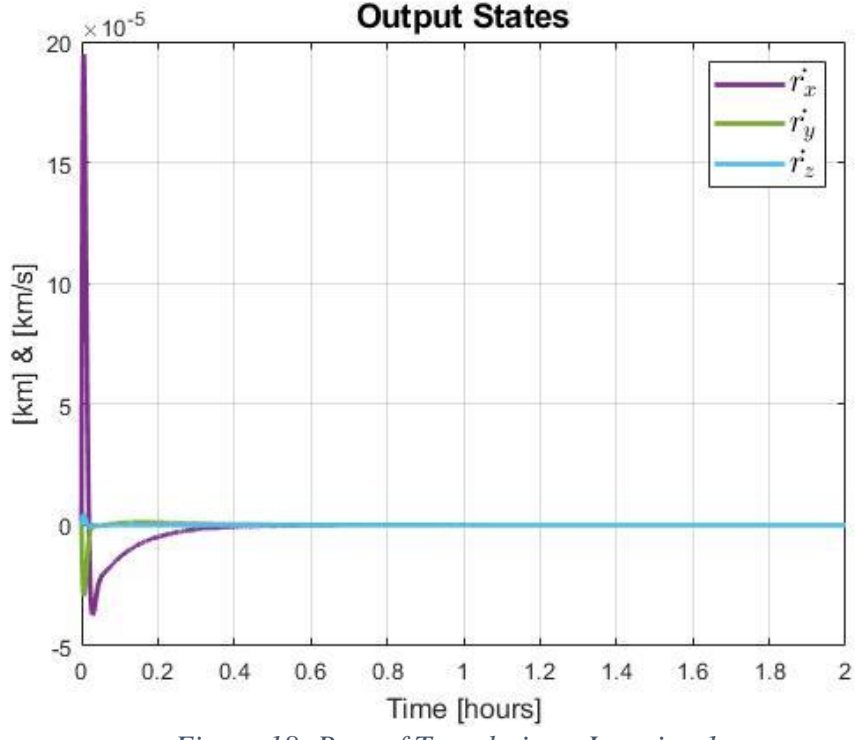

Figure 18: Rate of Translation - Iteration 1

4. The responses shown in Figure 17, 18 and 19, although, reduced the time needed for the system to reach a steady state response, the dynamics of the spacecraft would not be reasonable. Thus, sharp changes in any of the response plots is to be avoided as to not apply a large control torque and cause uncontrollable spinning of the spacecraft. 


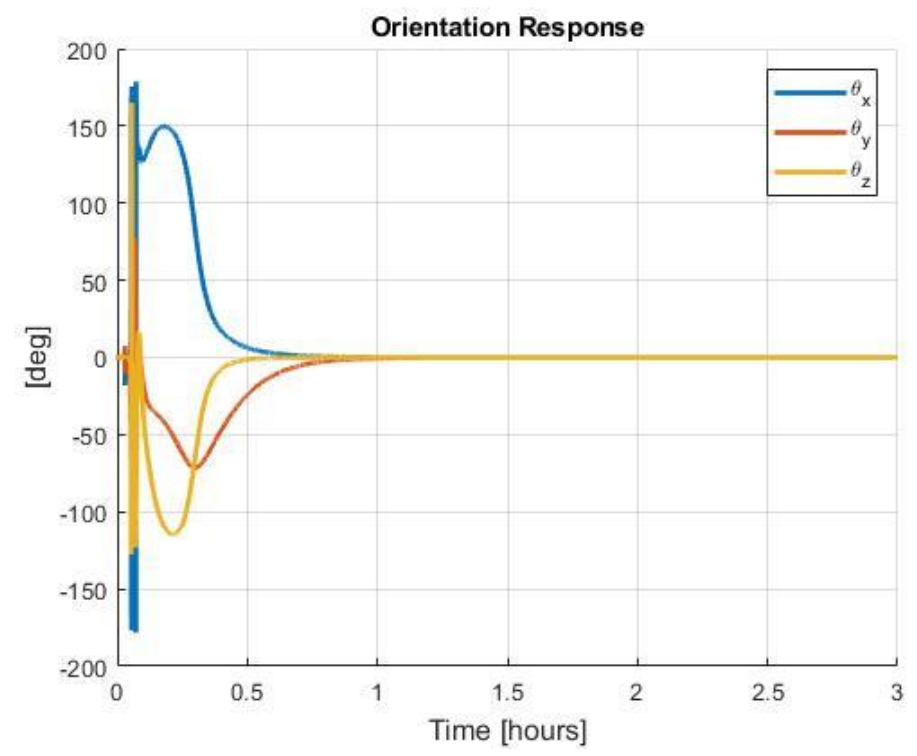

Figure 19: Orientation Response for Iteration 1

5. Following Steps 1-3 for a few more iterations, a value of $\mathbf{Q}=3 \mathrm{E} 07$ returns the following response plots:

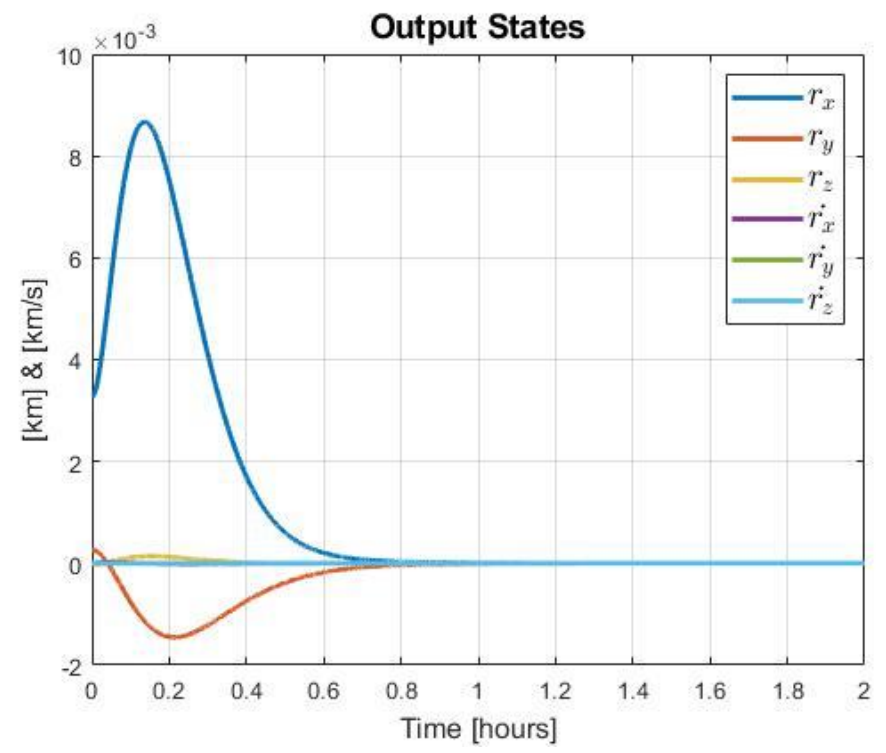

Figure 20: Translation Motion - Final Iteration

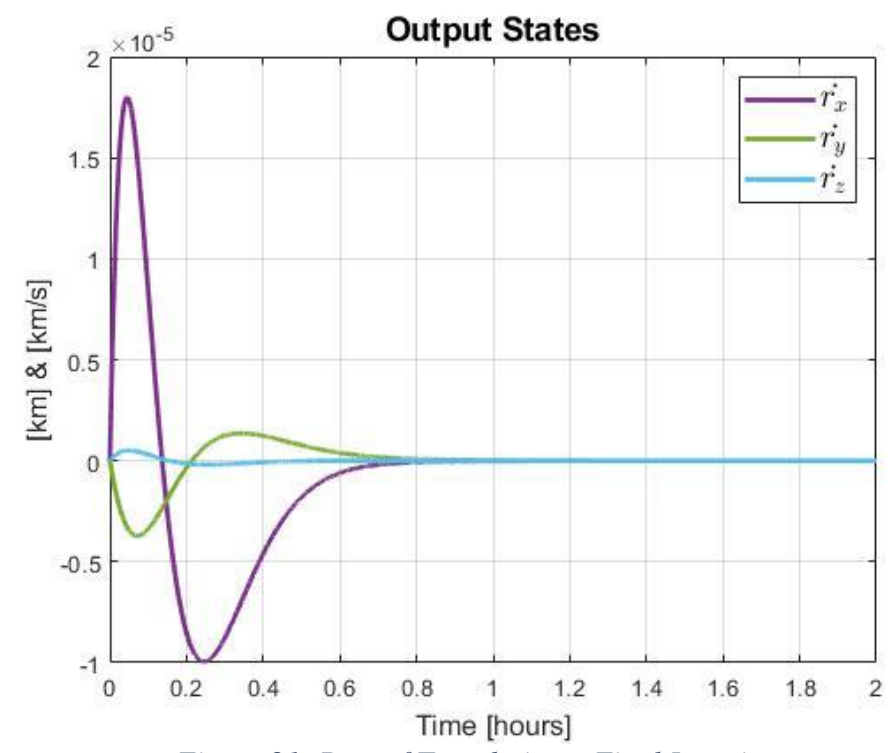

Figure 21: Rate of Translation - Final Iteration

6. The response plots obtained with the iterated value of $\mathbf{Q}$ shown in Figure 20, 21 and 22 shows a much more reasonable response while also reducing the time needed to reach a steady state response. The settling times of the initialized simulation, the first simulation and the final simulation are presented below in Table 1. 


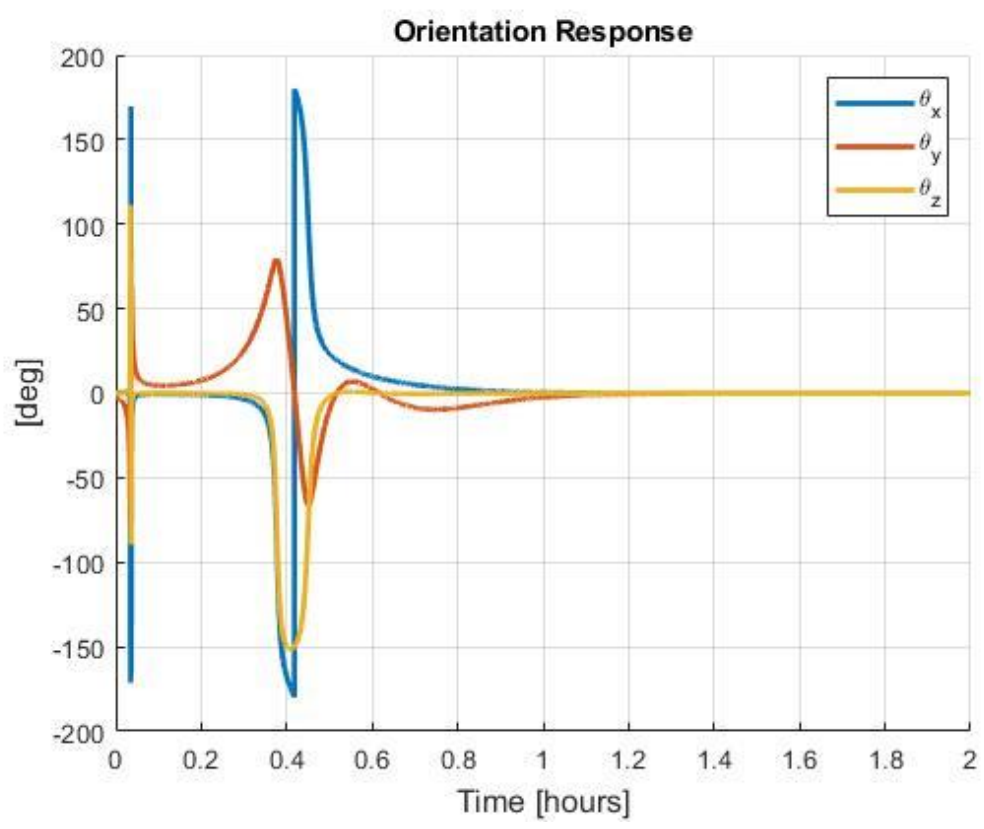

Figure 22: Orientation Response - Final Iteration

Table 1: Settling Times for Varying $Q$ and $R$ pairs

Settling Times (s)

\begin{tabular}{lccccc}
\hline Iteration & Position & Velocity & Euler Angles & Q & R \\
\hline \hline Initial & 3367 & 3392 & 3547 & $1 \mathrm{E}+10$ & $1 \mathrm{E}+06$ \\
$\mathbf{1}$ & 1986 & 806 & 2225 & $1 \mathrm{E}+12$ & $1 \mathrm{E}+00$ \\
Optimal & 2599 & 2378 & 2748 & $3 \mathrm{E}+07$ & $1 \mathrm{E}+00$ \\
\hline \hline
\end{tabular}

From Table 1, it can be seen that although higher values of $\mathbf{Q}$ reduces the settling times, the response and dynamics of the spacecraft may not necessarily be reasonable and thus the iteration procedure must consider both the settling times and the dynamics of the response plots through the iteration of $\mathbf{Q}$ and $\mathbf{R}$.

\subsection{Simulation Procedure - Summary}

In summary the iteration procedure is as follows:

1. Load the asteroid and spacecraft data onto the workspace, change the equilibrium point and orientation of the spacecraft as desired and run the scripts LQR_controller_initialization.m, the Simulink model system_block_diagram_closed_loop_LQR.slx and the script figures.m respectively.

2. Record the settling times of the initialized system.

3. Iterate the values of $\mathbf{Q}$ and $\mathbf{R}$ in $L_{Q R} Q_{-}$and_R_initialization.m, and run the script, the Simulink model and figures.m examining the response plots and iterating until a adequate combination of settling times and feasible response in obtained. 


\section{RESULTS}

Following the iteration procedure discussed in Section 4, each unique configuration of the spacecraft from the combination of equilibrium points and orientations at $1 \%, 2 \%$ and $5 \%$ perturbations were simulated. The following section presents and discusses the results obtained from the In-Plane Max and Radial Min orientations at a 1\% perturbation. Due to the large volume of data, the simulations conducted for all the remaining simulations are presented in Appendix A.

\section{$5.11 \%$ Perturbation}

\subsubsection{In Plane Max}

Table 2: Settling Times and Respective $Q \& R$ for each Equilibrium Point at In Plane Max

\begin{tabular}{llrrrrr} 
& & Position $(\mathbf{s})$ & Velocity $(\mathbf{s})$ & Euler Angles (s) & Q & R \\
\hline \hline \multirow{2}{*}{ E1 } & Initial & 3367 & 3392 & 3547 & $1 \mathrm{E}+10$ & $1 \mathrm{E}+06$ \\
& Optimal & 2599 & 2378 & 2748 & $3 \mathrm{E}+07$ & $1 \mathrm{E}+00$ \\
\hline \multirow{2}{*}{ E2 } & Initial & 4333 & 4136 & 4188 & $1 \mathrm{E}+10$ & $1 \mathrm{E}+06$ \\
& Optimal & 2380 & 2436 & 2829 & $1 \mathrm{E}+08$ & $1 \mathrm{E}+00$ \\
\hline \multirow{2}{*}{ E3 } & Initial & 2618 & 2729 & 3242 & $1 \mathrm{E}+10$ & $1 \mathrm{E}+06$ \\
& Optimal & 1367 & 1657 & 1833 & $3 \mathrm{E}+11$ & $1 \mathrm{E}+00$ \\
\hline \multirow{2}{*}{ E4 } & Initial & 3115 & 3322 & 3524 & $1 \mathrm{E}+10$ & $1 \mathrm{E}+06$ \\
& Optimal & 1951 & 2022 & 2479 & $6 \mathrm{E}+07$ & $1 \mathrm{E}+00$ \\
\hline \multirow{2}{*}{ E5 } & Initial & 2242 & 2630 & 2481 & $1 \mathrm{E}+10$ & $1 \mathrm{E}+06$ \\
& Optimal & 1719 & 1930 & 1491 & $1 \mathrm{E}+08$ & $1 \mathrm{E}+00$ \\
\hline \multirow{2}{*}{ E6 } & Initial & 4673 & 4648 & 4775 & $1 \mathrm{E}+10$ & $1 \mathrm{E}+06$ \\
& Optimal & 4313 & 3873 & 3586 & $2 \mathrm{E}+08$ & $1 \mathrm{E}+00$ \\
\hline E7 & Initial & 2389 & 2715 & 2707 & $1 \mathrm{E}+10$ & $1 \mathrm{E}+06$ \\
& Optimal & 1937 & 2051 & 1767 & $1 \mathrm{E}+08$ & $1 \mathrm{E}+00$ \\
\hline E8 & Initial & 2388 & 2709 & 2696 & $1 \mathrm{E}+10$ & $1 \mathrm{E}+06$ \\
& Optimal & 1936 & 2050 & 1762 & $1 \mathrm{E}+08$ & $1 \mathrm{E}+00$ \\
\hline \hline
\end{tabular}

Examining the initial and optimal settling times in Table 2 shows that the iteration procedure for $\mathbf{Q}$ and $\mathbf{R}$ was effective in reducing the settling times of the response. 


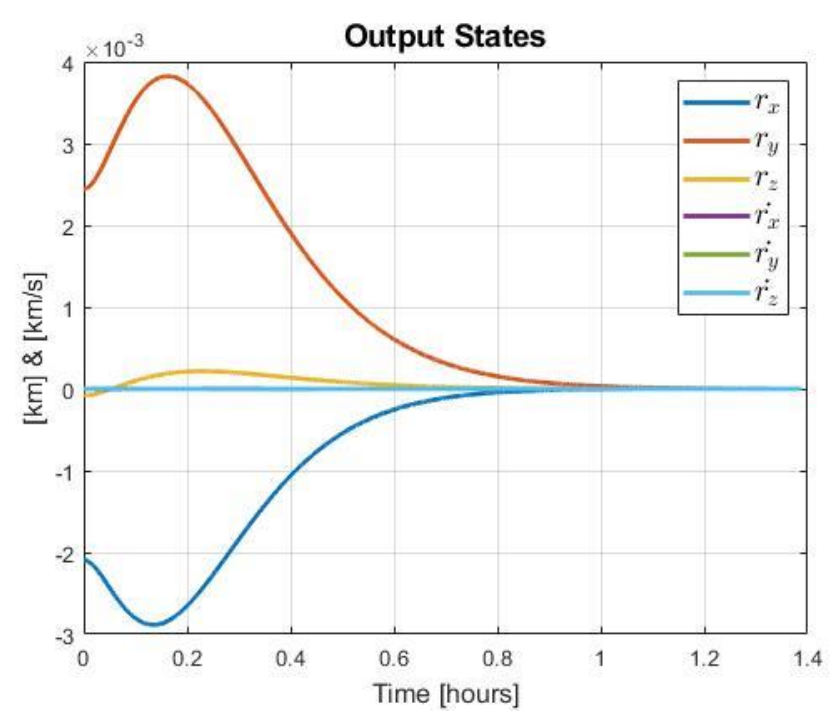

Figure 23: E4 Output States - Initial

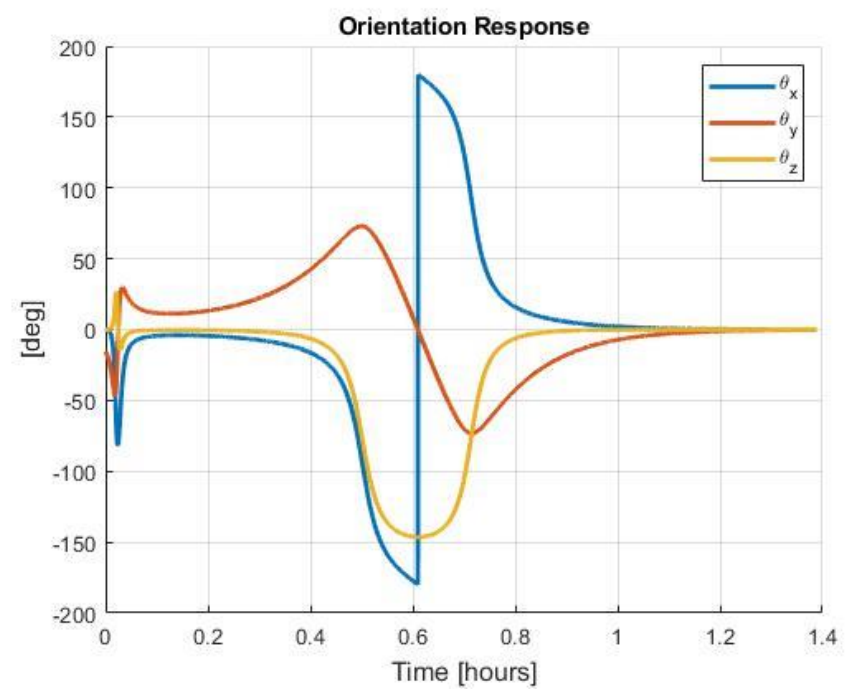

Figure 25: E4 Orientation Response - Initial

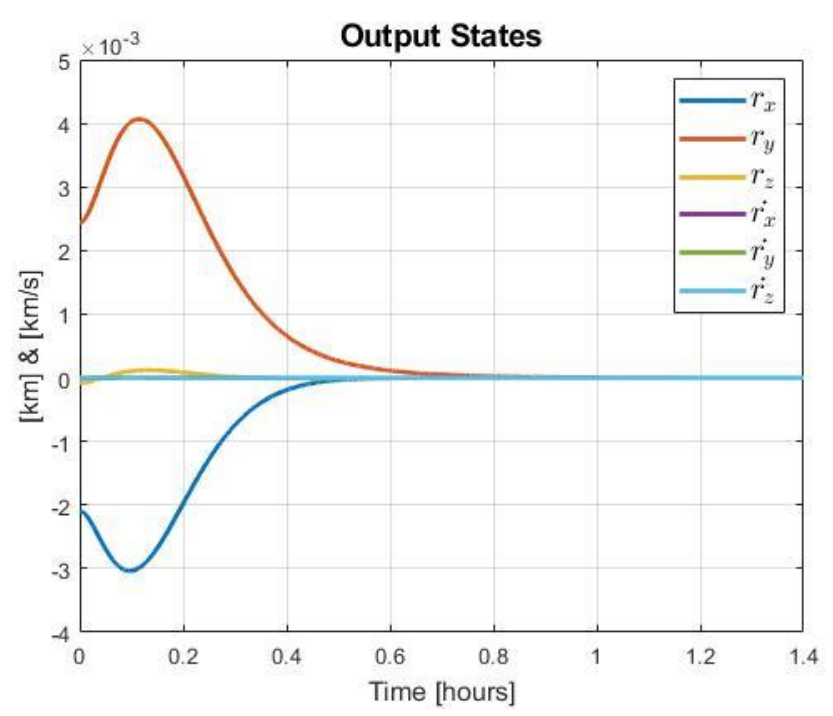

Figure 24: E4 Output States - Optimal

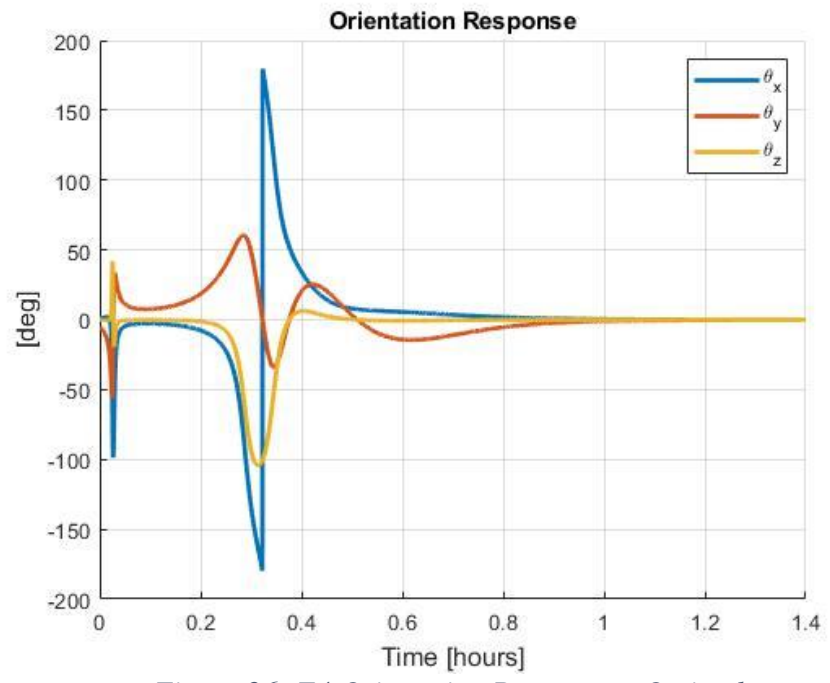

Figure 26: E4 Orientation Response-Optimal

Figures 23 to 26 demonstrate the response plots for the iterated $\mathbf{Q}$ and $\mathbf{R}$ values at equilibrium point E4 shown in Table 2. 


\subsubsection{Radial Min}

Table 3: Settling Times and Respective $Q \& R$ for each Equilibrium Point at Radial Min

\begin{tabular}{clccccc} 
& & Position (s) & Velocity (s) & Euler Angles (s) & Q & R \\
\hline \hline \multirow{2}{*}{ E1 } & Initial & 3052 & 3015 & 5174 & $1 \mathrm{E}+11$ & $1 \mathrm{E}+06$ \\
& Optimal & 2092 & 1951 & 4090 & $5 \mathrm{E}+09$ & $1 \mathrm{E}+00$ \\
\hline \multirow{2}{*}{ E2 } & Initial & 4814 & 4822 & 7004 & $1 \mathrm{E}+10$ & $1 \mathrm{E}+06$ \\
& Optimal & 2905 & 2707 & 5371 & $2 \mathrm{E}+09$ & $1 \mathrm{E}+00$ \\
\hline \multirow{2}{*}{ E3 } & Initial & 2860 & 2865 & 4683 & $1 \mathrm{E}+10$ & $1 \mathrm{E}+06$ \\
& Optimal & 2062 & 1950 & 3302 & $6 \mathrm{E}+08$ & $1 \mathrm{E}+00$ \\
\hline \multirow{2}{*}{ E4 } & Initial & 3189 & 2650 & 5744 & $1 \mathrm{E}+10$ & $1 \mathrm{E}+06$ \\
& Optimal & 2575 & 2142 & 4246 & $1 \mathrm{E}+09$ & $1 \mathrm{E}+00$ \\
\hline \multirow{2}{*}{ E5 } & Initial & 2424 & 2351 & 3850 & $1 \mathrm{E}+10$ & $1 \mathrm{E}+06$ \\
& Optimal & 1588 & 1571 & 2866 & $2 \mathrm{E}+10$ & $1 \mathrm{E}+00$ \\
\hline \multirow{2}{*}{ E6 } & Initial & 5684 & 5784 & 7862 & $1 \mathrm{E}+10$ & $1 \mathrm{E}+06$ \\
& Optimal & 3670 & 3819 & 5965 & $1 \mathrm{E}+09$ & $1 \mathrm{E}+00$ \\
\hline \multirow{2}{*}{ E7 } & Initial & 2326 & 2322 & 5047 & $1 \mathrm{E}+10$ & $1 \mathrm{E}+06$ \\
& Optimal & 1721 & 1724 & 3760 & $1 \mathrm{E}+11$ & $1 \mathrm{E}+00$ \\
\hline \multirow{2}{*}{ E8 } & Initial & 3078 & 3017 & 4926 & $1 \mathrm{E}+10$ & $1 \mathrm{E}+06$ \\
& Optimal & 2013 & 1992 & 3252 & $1 \mathrm{E}+10$ & $1 \mathrm{E}+00$ \\
\hline \hline
\end{tabular}

Table 3 presents the initial and optimal settling times in the Radial Min orientation with the respective $\mathbf{Q}$ and $\mathbf{R}$. The settling time for the position, velocity and orientations (Euler angles) are improved. 


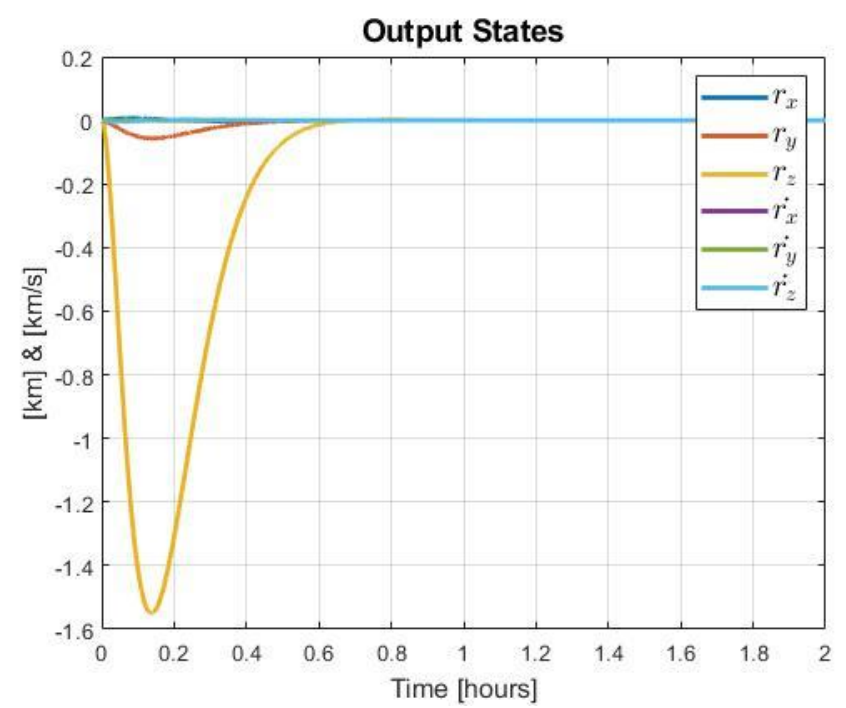

Figure 27: E7 Output States - Initial

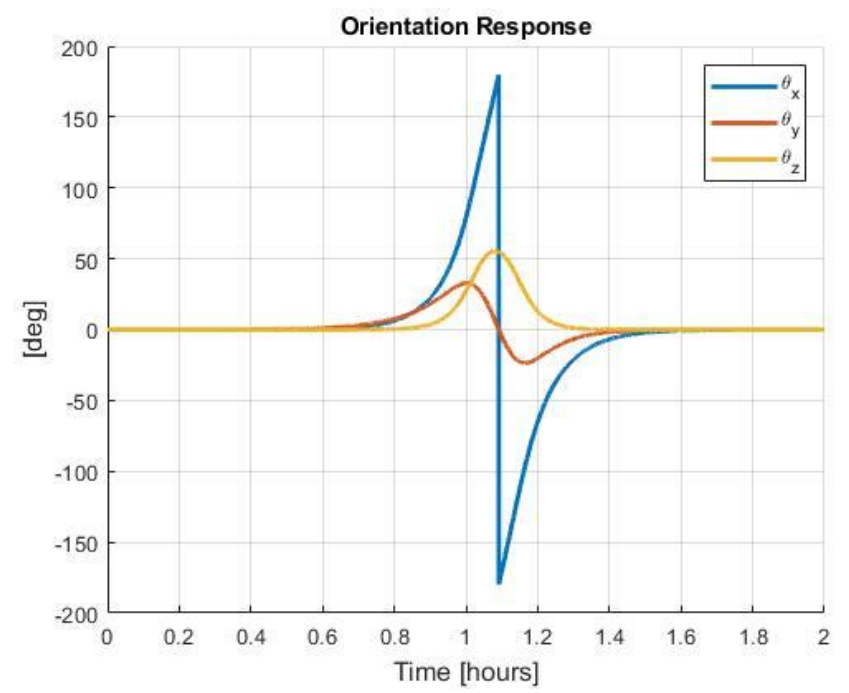

Figure 29: E7 Orientation Response - Initial

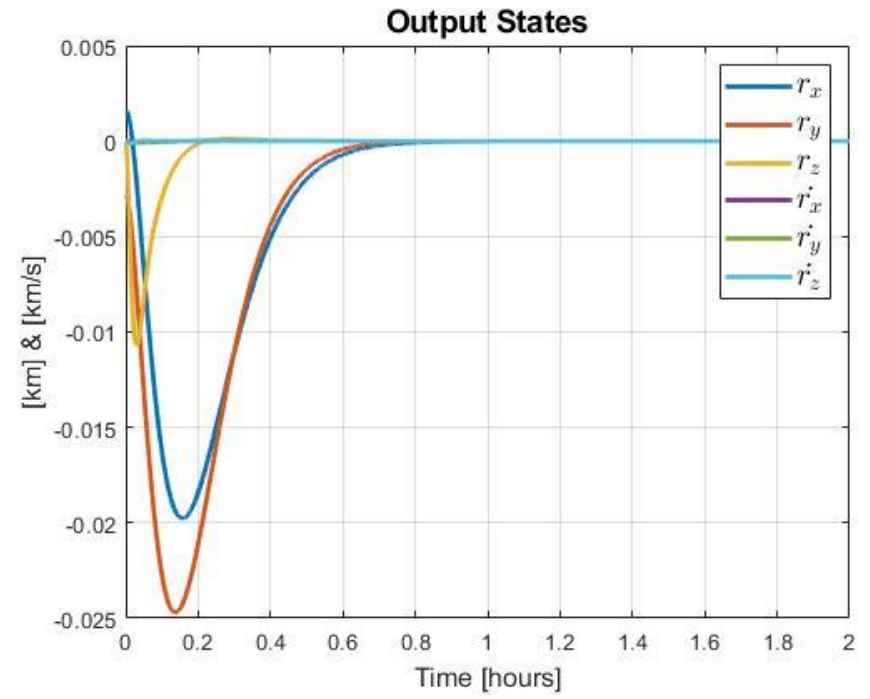

Figure 28: E7 Output States - Optimal

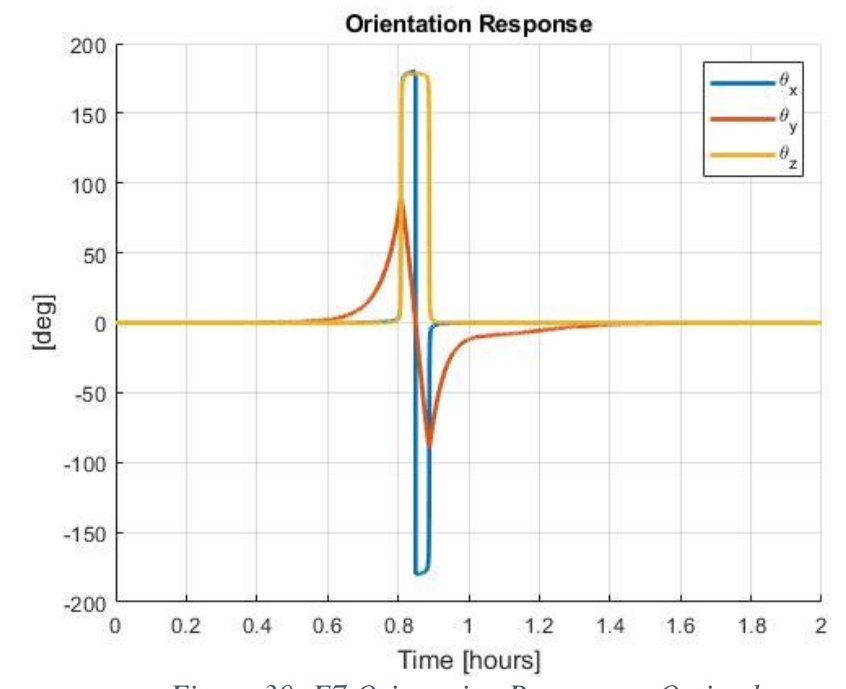

Figure 30: E7 Orientation Response - Optimal

Figures 23 to 26 demonstrate the response plots for the iterated $\mathbf{Q}$ and $\mathbf{R}$ values at equilibrium point E7 shown in Table 2. 


\section{ANALYSIS OF RESULTS}

The iteration procedure conducted for 144 possible scenarios' (48 configurations, 3 different perturbation) showed the following patterns:

- Proportionality of Q and R

- Common settling times for states regardless of perturbations

\subsection{Proportionality of $Q$ and $R$}

The relationship between $\mathbf{Q}$ and $\mathbf{R}$ is shown in Equation 2, where $\mathbf{Q}$ is the weighting matrix that penalized the states, while $\mathbf{R}$ is the weighting matrix that penalizes the control. Iterations throughout the project showed that settling times obtained from a $\mathbf{Q}$ and $\mathbf{R}$ pair were not unique and the same settling times could be found for a different $\mathbf{Q}$ and $\mathbf{R}$ pair. This relationship can be better examined from the results shown in Table 4.

Table 4: Settling Times for Varying $Q$ and $R$ Pairs

\begin{tabular}{cccccc}
\hline \hline Iteration & Position(s) & Velocity $(\mathbf{s})$ & Euler Angles $(\mathbf{s})$ & $\mathbf{Q}$ & $\mathbf{R}$ \\
\hline \hline $\mathbf{1}$ & 1734 & 1694 & 3543 & $1 \mathrm{E}+10$ & $1 \mathrm{E}+00$ \\
$\mathbf{2}$ & 1734 & 1694 & 3543 & $1 \mathrm{E}+12$ & $1 \mathrm{E}+02$ \\
$\mathbf{3}$ & 1734 & 1694 & 3543 & $1 \mathrm{E}+13$ & $1 \mathrm{E}+03$ \\
$\mathbf{4}$ & 1734 & 1694 & 3543 & $1 \mathrm{E}+07$ & $1 \mathrm{E}-03$ \\
\hline \hline
\end{tabular}

Table 4 depicts the simulations conducted for the Radial Min orientation at equilibrium point E5 at a 5\% perturbation. The results show that despite the varying $\mathbf{Q}$ and $\mathbf{R}$ pairs, the settling times of the simulation remains the same. Further examination of the $\mathbf{Q}$ and $\mathbf{R}$ pairs shows that the exponent of $\mathbf{R}$ subtracted from the exponent of $\mathbf{Q}$ always equals 10, or mathematically - letting $\mathbf{X}$ be the exponent of $\mathbf{Q}$ and y the exponent of $\mathbf{R}$ :

$$
x-y=10
$$

Generalizing the above relationship as:

$$
x-y=z
$$

Where $\mathrm{z}$ is an integer - for any integer combination of $\mathrm{x}$ and $\mathrm{y}$ that results in $\mathrm{z}$, the settling times of the system will be the same.

The response plots of the above iterations can also be verified to be the same: 


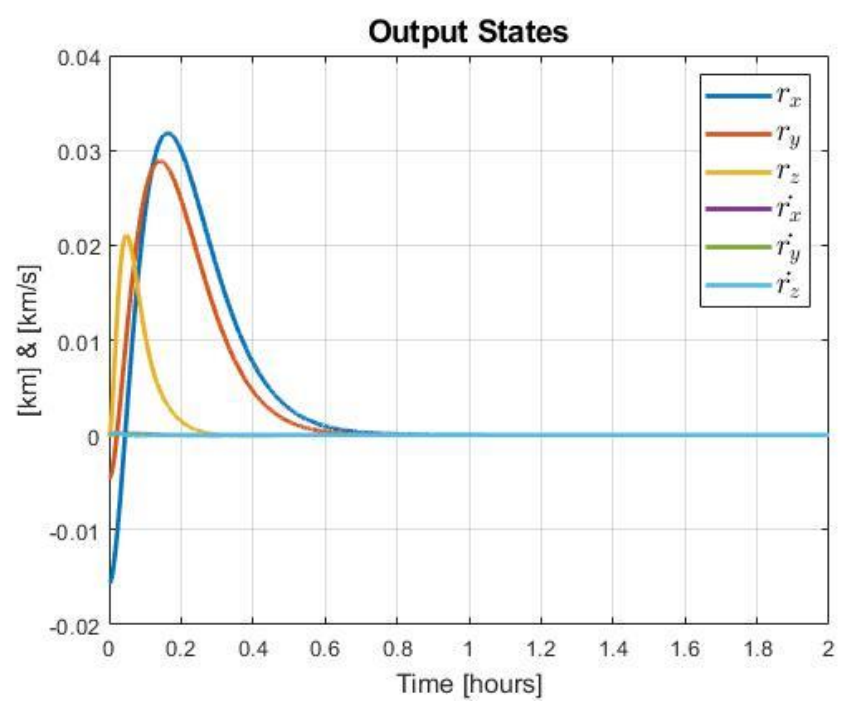

Figure 31: Output States - Iteration 1

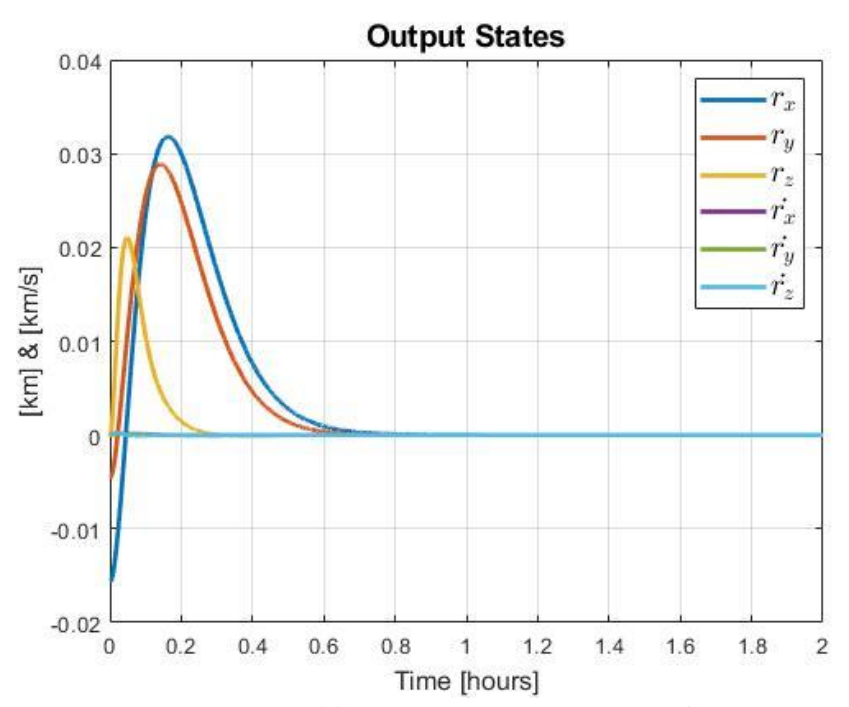

Figure 33: Output States - Iteration 4

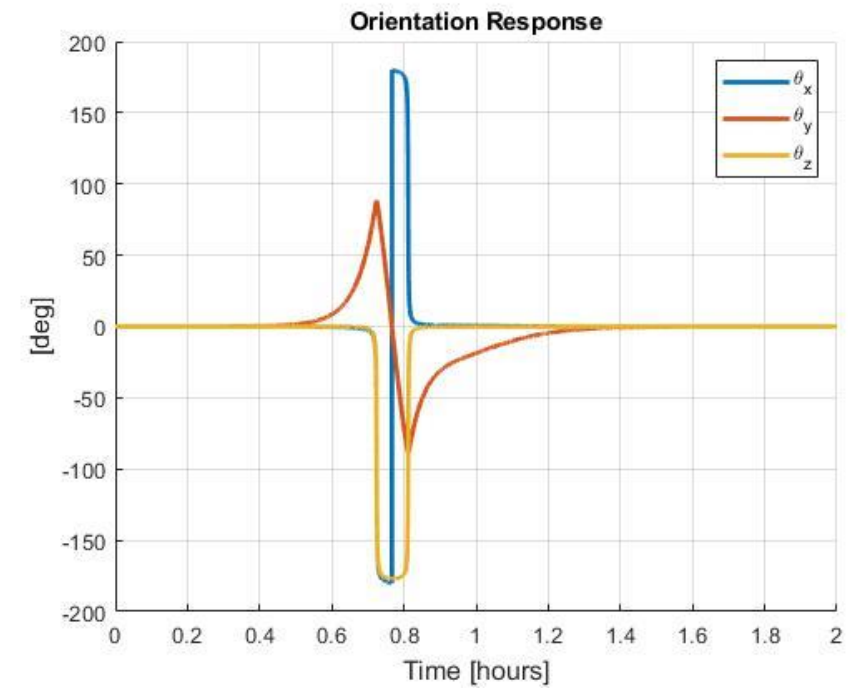

Figure 32: Orientation Response - Iteration 1

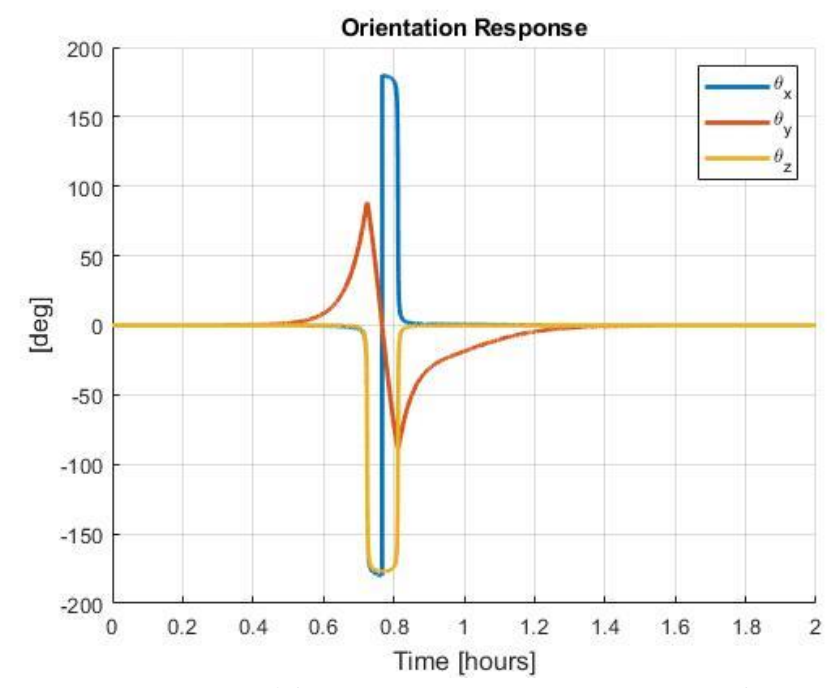

Figure 34: Orientation Response - Iteration 4

If a value of $\mathrm{z}$ is found that provides an ideal settling time and response plots combination, then $\mathrm{Q}$ and $\mathrm{R}$ values can be varied using the relationship in Equation 9 based on the mission requirements. The simulation procedures conducted here minimizes the penalty on control due to a limit on the control torque available, however for mission scenarios where further control torque may be available the weighing of $\mathrm{Q}$ and $\mathrm{R}$ can be adjusted resulting in the same system performance.

\subsection{Common Settling Times for States}

Another overlying pattern found through the iterations was that for a common configuration - the settling times for the Position and Velocity response was found to be the same for similar $\mathrm{Q}$ and $\mathrm{R}$ pairs but different perturbation values. This relationship is expanded upon in Table 5. 
Table 5: Settling Times for Varying Perturbations

\begin{tabular}{cccccc}
\hline \hline Perturbation & Position(s) & Velocity (s) & Euler Angles (s) & Q & R \\
\hline \hline $\mathbf{1 \%}$ & 4532 & 4530 & 5823 & $1 \mathrm{E}+10$ & $1 \mathrm{E}+06$ \\
$\mathbf{2 \%}$ & 4532 & 4530 & 6104 & $1 \mathrm{E}+10$ & $1 \mathrm{E}+06$ \\
$\mathbf{5 \%}$ & 4533 & 4531 & 6497 & $1 \mathrm{E}+10$ & $1 \mathrm{E}+06$ \\
\hline \hline
\end{tabular}

Table 4 presents the settling times at differing perturbations for the same $\mathrm{Q}$ and $\mathrm{R}$ pair at Out of Plane Max at E4. It can be observed that the settling times for translational motion is the same regardless of the perturbation whereas the settling times for rotational motion increases with perturbation. An increased perturbation means that the spacecraft is at a greater distance from the equilibrium point and if the time required to return to equilibrium is the same then the spacecraft must be travelling at a greater speed. Examining the Output States velocity response plots as shown in Figure 27, 29 and 31 shows this where the velocity in the $\mathrm{x}$ and $\mathrm{y}$ direction increases along with the perturbation. Despite the spacecraft arriving at the equilibrium point in the same amount of time, the spacecraft takes longer to return to its nominal orientation. This is likely due to a larger control torque being applied meaning the spacecraft takes longer to decelerate and settle into its original orientation. 


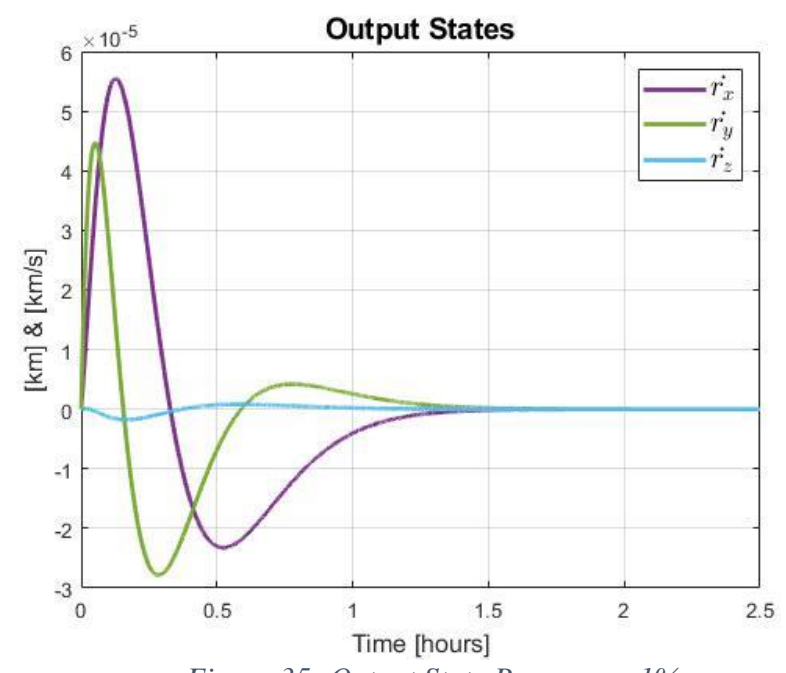

Figure 35: Output State Response - 1\%



Figure 37: Output State Response - 2\%

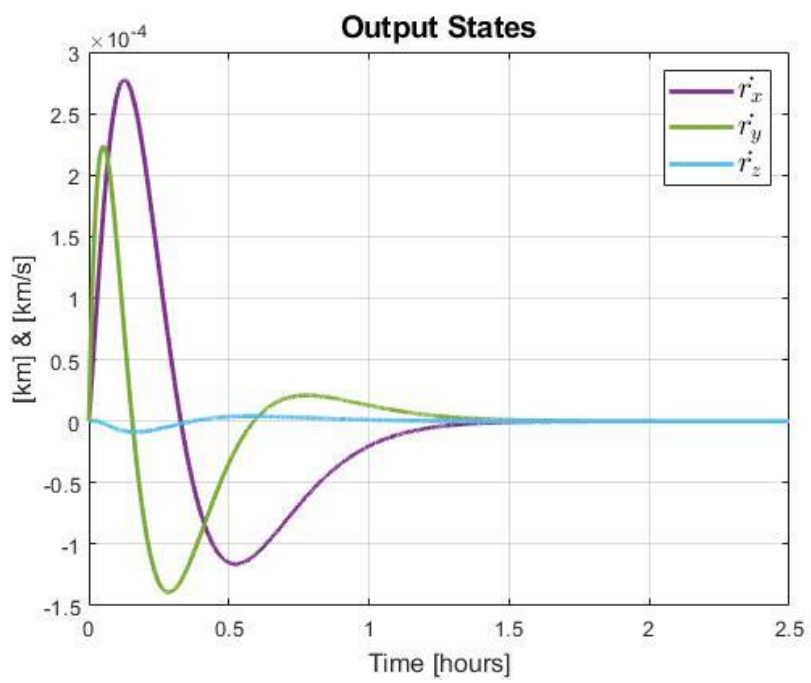

Figure 39: Output State Response - 5\%

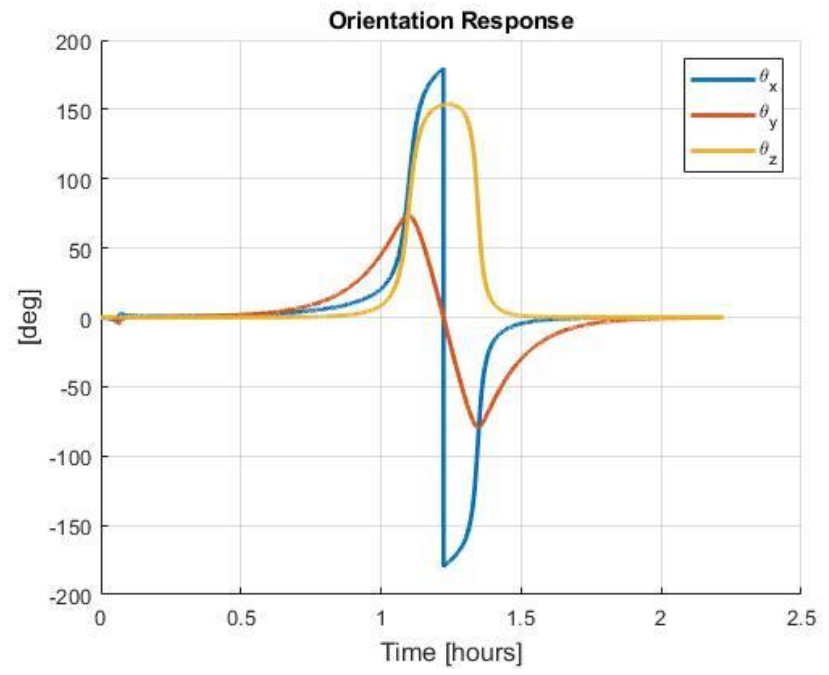

Figure 36: Orientation Response - 1\%

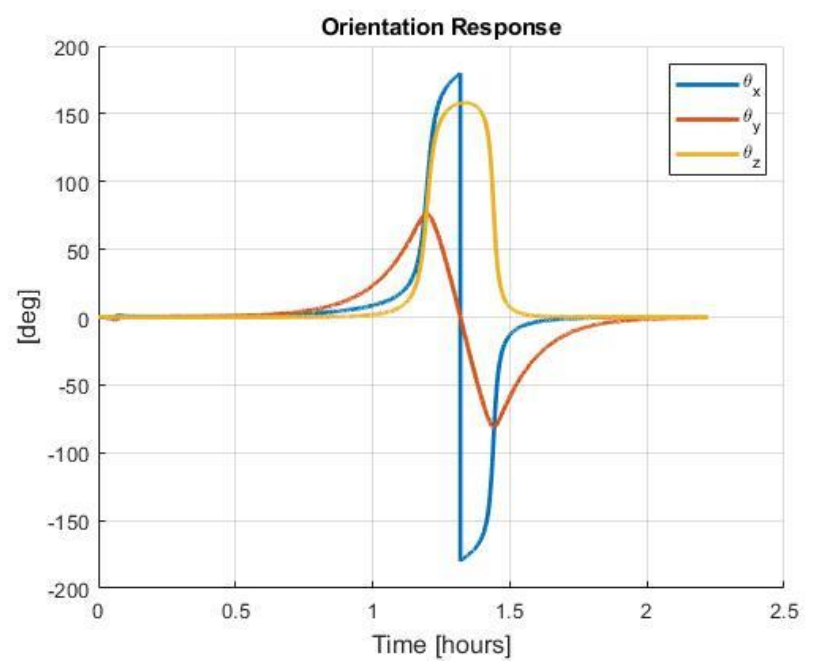

Figure 38: Orientation Response - 2\%

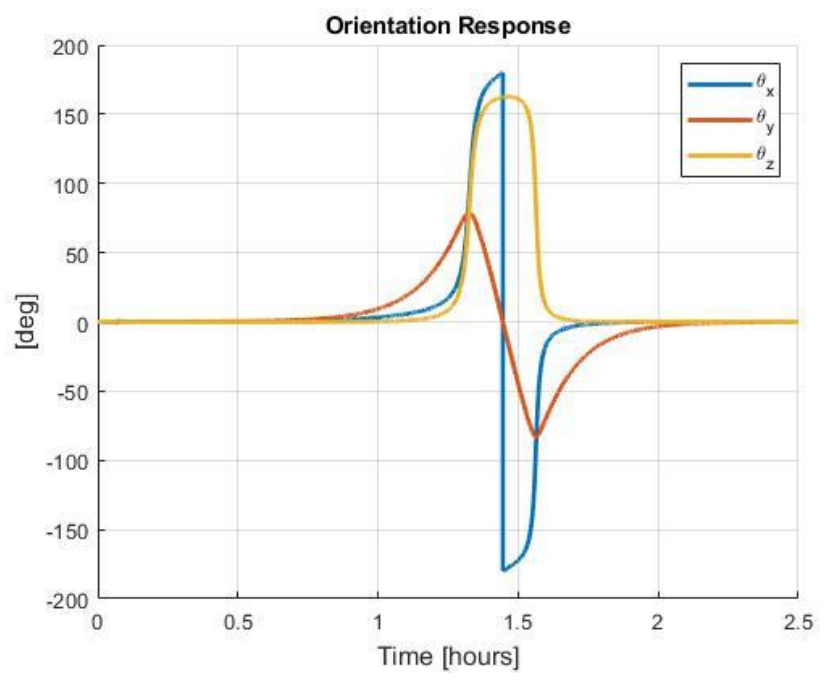

Figure 40: Orientation Response - 5\% 


\section{CONCLUSION}

This thesis project presents the simulations of a spacecraft about varying equilibrium points of the asteroid 101955 Bennu. Underlying control theory states that a typically non-linear system can be linearized given that the system operates about an equilibrium point and the signals are small. Furthermore, the linearized system can considered to be equivalent to the non-linear system within a limited operating range. Following this precedent, this project applied a closed loop LQR controller to spacecraft perturbations of $1 \%, 2 \%$ and $5 \%$ from each of the eight different asteroid equilibrium points. Subsequently, the LQR methodology requires that weighting matrices $\mathbf{Q}$ and $\mathbf{R}$ be iterated upon based on the system requirements which was the primary objective of this project. The iteration procedure is presented in Section 4 and uses the settling time and plots of the system response to assess the controller performance. The results obtained from the simulations are tabulated and presented in Section 5 and Appendix A. Some patterns observed from the simulations were:

- proportionality of $\mathbf{Q}$ and $\mathbf{R}$ : settling times obtained from a $\mathbf{Q}$ and $\mathbf{R}$ pair were not unique and the same settling times could be found for a different $\mathbf{Q}$ and $\mathbf{R}$ pair

- common settling times for different perturbations: for a common configuration - the settling times for the Position and Velocity response was found to be the same with similar $\mathrm{Q}$ and $\mathrm{R}$ pairs but different perturbation values.

This project presents the results based on linearized spacecraft dynamics and simulations for nonlinear spacecraft dynamics can be found in [3]. 


\section{BIBLIOGRAPHY}

[1] K. W. Lee and S. N. Singh, "Quaternion-based adaptive attitude control of asteroid-orbiting spacecraft via immersion and invariance," Acta Astronautica, pp. 164--180, 2020.

[2] Y. Wang and S. Xu, "Body-fixed orbit attitude hovering control over an asteroid using noncanonical Hamiltonian structure," Acta Astronautica, pp. 450-468, 2015.

[3] D. A. Bolatti, "PhD Dissertation," Unpublished, Toronto, 2020.

[4] K. Ogata and Y. Yang, Modern Controls Engineering, Upper Saddle River, NJ: Prentice Hall, 2010 .

[5] D. A. Bolatti, "Quantification of attitude effects on orbital dynamics near asteroids," Acta Astronautica, vol. 167, pp. 467-482, 2020. 
APPENDIX A - SIMULATION RESULTS

\section{A.1 1\% Perturbation}

\section{A.1.2 In Plane Min}

Table 6: Settling Times and Respective $Q \& R$ for each Equilibrium Point at In Plane Min-1\%

\begin{tabular}{llrcccc} 
& & Position (s) & Velocity (s) & Euler Angles (s) & $\mathrm{Q}$ & $\mathrm{R}$ \\
\hline \hline $\mathbf{E} 1$ & Initial & 3367 & 3392 & 3596 & $1 \mathrm{E}+10$ & $1 \mathrm{E}+06$ \\
& Optimal & 2562 & 2274 & 2838 & $4 \mathrm{E}+07$ & $1 \mathrm{E}+00$ \\
\hline E2 & Initial & 4116 & 4304 & 4460 & $1 \mathrm{E}+10$ & $1 \mathrm{E}+06$ \\
& Optimal & 2528 & 2611 & 3496 & $5 \mathrm{E}+07$ & $1 \mathrm{E}+00$ \\
\hline $\mathbf{E 3}$ & Initial & 2618 & 2729 & 3372 & $1 \mathrm{E}+10$ & $1 \mathrm{E}+06$ \\
& Optimal & 1746 & 1903 & 2345 & $3 \mathrm{E}+07$ & $1 \mathrm{E}+00$ \\
\hline \multirow{2}{*}{ E4 } & Initial & 3115 & 3323 & 3586 & $1 \mathrm{E}+10$ & $1 \mathrm{E}+06$ \\
& Optimal & 1952 & 2023 & 2435 & $1 \mathrm{E}+08$ & $1 \mathrm{E}+00$ \\
\hline \multirow{2}{*}{ E5 } & Initial & 2242 & 2630 & 2705 & $1 \mathrm{E}+10$ & $1 \mathrm{E}+06$ \\
& Optimal & 1719 & 1930 & 2040 & $1 \mathrm{E}+08$ & $1 \mathrm{E}+00$ \\
\hline E6 & Initial & 4739 & 5226 & 4981 & $1 \mathrm{E}+10$ & $1 \mathrm{E}+06$ \\
& Optimal & 4552 & 4090 & 3872 & $1 \mathrm{E}+08$ & $1 \mathrm{E}+00$ \\
\hline \multirow{2}{*}{ E7 } & Initial & 2389 & 2716 & 1187 & $1 \mathrm{E}+10$ & $1 \mathrm{E}+06$ \\
& Optimal & 1937 & 2051 & 1935 & $1 \mathrm{E}+08$ & $1 \mathrm{E}+00$ \\
\hline \multirow{2}{*}{ E8 } & Initial & 2389 & 2715 & 1187 & $1 \mathrm{E}+10$ & $1 \mathrm{E}+06$ \\
& Optimal & 1937 & 2051 & 1935 & $1 \mathrm{E}+08$ & $1 \mathrm{E}+00$ \\
\hline \hline
\end{tabular}

\section{A.1.3 Radial Max}

Table 7: Settling Times and Respective $Q \& R$ for each Equilibrium Point at Radial Max - $1 \%$

\begin{tabular}{clccccc} 
& & Position (s) & Velocity (s) & Euler Angles (s) & Q & R \\
\hline \hline E1 & Initial & 3544 & 3545 & 4578 & $1 \mathrm{E}+10$ & $1 \mathrm{E}+06$ \\
& Optimal & 2555 & 2671 & 3494 & $3 \mathrm{E}+07$ & $1 \mathrm{E}+00$ \\
\hline \multirow{2}{*}{ E2 } & Initial & 4517 & 4492 & 5487 & $1 \mathrm{E}+10$ & $1 \mathrm{E}+06$ \\
& Optimal & 3217 & 3080 & 4148 & $2 \mathrm{E}+07$ & $1 \mathrm{E}+00$ \\
\hline \multirow{2}{*}{ E3 } & Initial & 2928 & 3057 & 4386 & $1 \mathrm{E}+10$ & $1 \mathrm{E}+06$ \\
& Optimal & 2244 & 2217 & 3081 & $3 \mathrm{E}+07$ & $1 \mathrm{E}+00$ \\
\hline \multirow{2}{*}{ E4 } & Initial & 4013 & 4032 & 5524 & $1 \mathrm{E}+10$ & $1 \mathrm{E}+00$ \\
& Optimal & 2471 & 2133 & 3902 & $2 \mathrm{E}+08$ & $1 \mathrm{E}+00$ \\
\hline \multirow{2}{*}{ E5 } & Initial & 2543 & 2562 & 3702 & $1 \mathrm{E}+10$ & $1 \mathrm{E}+06$ \\
& Optimal & 1870 & 1991 & 2749 & $3 \mathrm{E}+07$ & $1 \mathrm{E}+00$ \\
\hline \multirow{2}{*}{ E6 } & Initial & 5720 & 5749 & 6304 & $1 \mathrm{E}+10$ & $1 \mathrm{E}+06$ \\
& Optimal & 4137 & 4116 & 4740 & $2 \mathrm{E}+07$ & $1 \mathrm{E}+00$ \\
\hline \multirow{2}{*}{ E7 } & Initial & 2597 & 2602 & 3708 & $1 \mathrm{E}+10$ & $1 \mathrm{E}+06$ \\
& Optimal & 1924 & 1872 & 2501 & $4 \mathrm{E}+07$ & $1 \mathrm{E}+00$ \\
\hline \multirow{2}{*}{ E8 } & Initial & 3938 & 3917 & 4698 & $1 \mathrm{E}+10$ & $1 \mathrm{E}+06$ \\
& Optimal & 2882 & 2856 & 3730 & $4 \mathrm{E}+07$ & $1 \mathrm{E}+00$ \\
\hline \hline
\end{tabular}




\section{A.1.5 Out of Plane Max}

Table 8: Settling Times and Respective Q \& R for each Equilibrium Point at Out of Plane Max - 1\%

\begin{tabular}{clccccc} 
& & Position $(\mathbf{s})$ & Velocity $(\mathbf{s})$ & Euler Angles (s) & $\mathbf{Q}$ & $\mathbf{R}$ \\
\hline \hline $\mathbf{E 1}$ & Initial & 2699 & 2888 & 4968 & $1 \mathrm{E}+10$ & $1 \mathrm{E}+06$ \\
& Optimal & 1783 & 1288 & 2744 & $1 \mathrm{E}+10$ & $1 \mathrm{E}+00$ \\
\hline \multirow{2}{*}{ E2 } & Initial & 4756 & 4765 & 5597 & $1 \mathrm{E}+10$ & $1 \mathrm{E}+06$ \\
& Optimal & 2446 & 2390 & 3829 & $3 \mathrm{E}+08$ & $1 \mathrm{E}+00$ \\
\hline \multirow{2}{*}{ E3 } & Initial & 2858 & 2849 & 4675 & $1 \mathrm{E}+10$ & $1 \mathrm{E}+06$ \\
& Optimal & 1837 & 1347 & 2804 & $2 \mathrm{E}+09$ & $1 \mathrm{E}+00$ \\
\hline $\mathbf{E 4}$ & Initial & 4532 & 4530 & 5823 & $1 \mathrm{E}+10$ & $1 \mathrm{E}+06$ \\
& Optimal & 2836 & 2952 & 4424 & $5 \mathrm{E}+07$ & $1 \mathrm{E}+00$ \\
\hline \multirow{2}{*}{$\mathbf{E 5}$} & Initial & 2865 & 2907 & 4103 & $1 \mathrm{E}+10$ & $1 \mathrm{E}+06$ \\
& Optimal & 1980 & 2376 & 3091 & $1 \mathrm{E}+08$ & $1 \mathrm{E}+00$ \\
\hline \multirow{2}{*}{ E6 } & Initial & 6587 & 6568 & 7531 & $1 \mathrm{E}+10$ & $1 \mathrm{E}+06$ \\
& Optimal & 3346 & 3215 & 5174 & $2 \mathrm{E}+08$ & $1 \mathrm{E}+00$ \\
\hline \multirow{2}{*}{ E7 } & Initial & 2776 & 2785 & 4024 & $1 \mathrm{E}+10$ & $1 \mathrm{E}+06$ \\
& Optimal & 1965 & 1938 & 2981 & $1 \mathrm{E}+08$ & $1 \mathrm{E}+00$ \\
\hline \multirow{2}{*}{ E8 } & Initial & 3546 & 3489 & 4286 & $1 \mathrm{E}+10$ & $1 \mathrm{E}+06$ \\
& Optimal & 4289 & 1325 & 3003 & $6 \mathrm{E}+08$ & $1 \mathrm{E}+00$ \\
\hline \hline
\end{tabular}

\section{A.1.6 Out of Plane Min}

Table 9: Settling Times and Respective $Q \& R$ for each Equilibrium Point at Out of Plane Min - 1\%

\begin{tabular}{|c|c|c|c|c|c|c|}
\hline & & Position (s) & Velocity (s) & Euler Angles (s) & $\mathbf{Q}$ & $\mathbf{R}$ \\
\hline \multirow[t]{2}{*}{$\bar{E}$ E1 } & Initial & 2699 & 2888 & 4829 & $1 \mathrm{E}+10$ & $1 \mathrm{E}+06$ \\
\hline & Optimal & 1783 & 1288 & 2821 & $1 E+10$ & $1 \mathrm{E}+00$ \\
\hline \multirow[t]{2}{*}{ E2 } & Initial & 4742 & 5081 & 5901 & $1 \mathrm{E}+10$ & $1 \mathrm{E}+06$ \\
\hline & Optimal & 2345 & 2220 & 3865 & $5 E+08$ & $1 \mathrm{E}+00$ \\
\hline \multirow[t]{2}{*}{ E3 } & Initial & 2858 & 2849 & 4202 & $1 E+10$ & $1 \mathrm{E}+06$ \\
\hline & Optimal & 1921 & 1454 & 2814 & $1 \mathrm{E}+09$ & $1 \mathrm{E}+00$ \\
\hline \multirow[t]{2}{*}{ E4 } & Initial & 4532 & 4530 & 5078 & $1 E+10$ & $1 \mathrm{E}+00$ \\
\hline & Optimal & 2866 & 2655 & 4234 & $1 \mathrm{E}+08$ & $1 \mathrm{E}+00$ \\
\hline \multirow[t]{2}{*}{ E5 } & Initial & 2865 & 2907 & 4216 & $1 \mathrm{E}+10$ & $1 \mathrm{E}+06$ \\
\hline & Optimal & 1980 & 2043 & 3104 & $1 \mathrm{E}+08$ & $1 \mathrm{E}+00$ \\
\hline \multirow[t]{2}{*}{ E6 } & Initial & 6587 & 6568 & 7844 & $1 E+10$ & $1 \mathrm{E}+06$ \\
\hline & Optimal & 3150 & 2893 & 5296 & $4 \mathrm{E}+08$ & $1 \mathrm{E}+00$ \\
\hline \multirow[t]{2}{*}{ E7 } & Initial & 2776 & 2785 & 4142 & $1 \mathrm{E}+10$ & $1 \mathrm{E}+06$ \\
\hline & Optimal & 2055 & 2110 & 3298 & $3 E+07$ & $1 \mathrm{E}+00$ \\
\hline \multirow[t]{2}{*}{ E8 } & Initial & 3546 & 3489 & 4826 & $1 \mathrm{E}+10$ & $1 \mathrm{E}+06$ \\
\hline & Optimal & 1884 & 1869 & 2874 & $1 \mathrm{E}+08$ & $1 \mathrm{E}+00$ \\
\hline
\end{tabular}




\section{A.2 2\% Perturbation}

\section{A.2.1 In Plane Max}

Table 10: Settling Times and Respective $Q \& R$ for each Equilibrium Point at In Plane Max - 2\%

\begin{tabular}{clccccc} 
& & Position (s) & Velocity (s) & Euler Angles (s) & Q & R \\
\hline \hline \multirow{2}{*}{ E1 } & Initial & 3367 & 3392 & 3803 & $1 \mathrm{E}+10$ & $1 \mathrm{E}+06$ \\
& Optimal & 2417 & 2534 & 3126 & $2 \mathrm{E}+07$ & $1 \mathrm{E}+00$ \\
\hline \multirow{2}{*}{ E2 } & Initial & 4115 & 4303 & 4741 & $1 \mathrm{E}+10$ & $1 \mathrm{E}+06$ \\
& Optimal & 2654 & 2804 & 4044 & $2 \mathrm{E}+07$ & $1 \mathrm{E}+00$ \\
\hline \multirow{2}{*}{ E3 } & Initial & 2618 & 2729 & 3476 & $1 \mathrm{E}+10$ & $1 \mathrm{E}+06$ \\
& Optimal & 1886 & 2042 & 2663 & $2 \mathrm{E}+07$ & $1 \mathrm{E}+00$ \\
\hline \multirow{2}{*}{$\mathbf{E 4}$} & Initial & 3115 & 3322 & 3780 & $1 \mathrm{E}+10$ & $1 \mathrm{E}+06$ \\
& Optimal & 1951 & 2022 & 2970 & $1 \mathrm{E}+08$ & $1 \mathrm{E}+00$ \\
\hline \multirow{2}{*}{ E5 } & Initial & 2242 & 2630 & 2712 & $1 \mathrm{E}+10$ & $1 \mathrm{E}+06$ \\
& Optimal & 1897 & 2215 & 2079 & $1 \mathrm{E}+07$ & $1 \mathrm{E}+00$ \\
\hline \multirow{2}{*}{ E6 } & Initial & 4613 & 4970 & 5046 & $1 \mathrm{E}+10$ & $1 \mathrm{E}+06$ \\
& Optimal & 4584 & 4775 & 4467 & $1 \mathrm{E}+07$ & $1 \mathrm{E}+00$ \\
\hline \multirow{2}{*}{ E7 } & Initial & 2389 & 2716 & 2960 & $1 \mathrm{E}+10$ & $1 \mathrm{E}+06$ \\
& Optimal & 1922 & 2192 & 2242 & $1 \mathrm{E}+07$ & $1 \mathrm{E}+00$ \\
\hline \multirow{2}{*}{ E8 } & Initial & 2389 & 2715 & 2956 & $1 \mathrm{E}+10$ & $1 \mathrm{E}+06$ \\
& Optimal & 2046 & 4195 & 2011 & $4 \mathrm{E}+07$ & $1 \mathrm{E}+00$ \\
\hline \hline
\end{tabular}

\section{A.2.2 In Plane Min}

Table 11: Settling Times and Respective $Q \& R$ for each Equilibrium Point at In Plane Min-2\%

\begin{tabular}{clrcccc} 
& & Position (s) & Velocity (s) & Euler Angles (s) & Q & R \\
\hline \hline \multirow{2}{*}{ E1 } & Initial & 3367 & 3392 & 3765 & $1 \mathrm{E}+10$ & $1 \mathrm{E}+06$ \\
& Optimal & 2599 & 2378 & 3079 & $3 \mathrm{E}+07$ & $1 \mathrm{E}+00$ \\
\hline \multirow{2}{*}{ E2 } & Initial & 4115 & 4303 & 4782 & $1 \mathrm{E}+10$ & $1 \mathrm{E}+06$ \\
& Optimal & 2497 & 2623 & 3939 & $3 \mathrm{E}+07$ & $1 \mathrm{E}+00$ \\
\hline \multirow{2}{*}{ E3 } & Initial & 2618 & 2729 & 3676 & $1 \mathrm{E}+10$ & $1 \mathrm{E}+06$ \\
& Optimal & 1886 & 2042 & 2611 & $2 \mathrm{E}+07$ & $1 \mathrm{E}+00$ \\
\hline \multirow{2}{*}{$\mathbf{E 4}$} & Initial & 3121 & 3331 & 3968 & $1 \mathrm{E}+10$ & $1 \mathrm{E}+06$ \\
& Optimal & 2062 & 2114 & 2780 & $6 \mathrm{E}+07$ & $1 \mathrm{E}+00$ \\
\hline \multirow{2}{*}{ E5 } & Initial & 2242 & 2630 & 2893 & $1 \mathrm{E}+10$ & $1 \mathrm{E}+06$ \\
& Optimal & 1785 & 2021 & 2409 & $5 \mathrm{E}+07$ & $1 \mathrm{E}+00$ \\
\hline \multirow{2}{*}{ E6 } & Initial & 4736 & 5212 & 5408 & $1 \mathrm{E}+10$ & $1 \mathrm{E}+06$ \\
& Optimal & 4639 & 4281 & 4410 & $5 \mathrm{E}+07$ & $1 \mathrm{E}+00$ \\
\hline \multirow{2}{*}{ E7 } & Initial & 2389 & 2716 & 1258 & $1 \mathrm{E}+10$ & $1 \mathrm{E}+06$ \\
& Optimal & 2060 & 1749 & 1780 & $3 \mathrm{E}+07$ & $1 \mathrm{E}+00$ \\
\hline \multirow{2}{*}{ E8 } & Initial & 2389 & 2716 & 1258 & $1 \mathrm{E}+10$ & $1 \mathrm{E}+06$ \\
& Optimal & 1863 & 1941 & 1992 & $2 \mathrm{E}+08$ & $1 \mathrm{E}+00$ \\
\hline \hline
\end{tabular}




\section{A.2.3 Radial Max}

Table 12: Settling Times and Respective $Q \& R$ for each Equilibrium Point at Radial Max-2\%

\begin{tabular}{clccccc} 
& & Position (s) & Velocity (s) & Euler Angles (s) & Q & R \\
\hline \hline \multirow{2}{*}{ E1 } & Initial & 3544 & 3545 & 4934 & $1 \mathrm{E}+10$ & $1 \mathrm{E}+06$ \\
& Optimal & 2713 & 2823 & 3650 & $2 \mathrm{E}+07$ & $1 \mathrm{E}+00$ \\
\hline \multirow{2}{*}{ E2 } & Initial & 4524 & 4501 & 5895 & $1 \mathrm{E}+10$ & $1 \mathrm{E}+06$ \\
& Optimal & 3335 & 3442 & 4574 & $1 \mathrm{E}+07$ & $1 \mathrm{E}+00$ \\
\hline \multirow{2}{*}{ E3 } & Initial & 2928 & 3057 & 4689 & $1 \mathrm{E}+10$ & $1 \mathrm{E}+06$ \\
& Optimal & 2602 & 2603 & 3984 & $1 \mathrm{E}+07$ & $1 \mathrm{E}+00$ \\
\hline \multirow{2}{*}{ E4 } & Initial & 4015 & 4034 & 5844 & $1 \mathrm{E}+10$ & $1 \mathrm{E}+06$ \\
& Optimal & 2926 & 3035 & 4295 & $2 \mathrm{E}+07$ & $1 \mathrm{E}+00$ \\
\hline \multirow{2}{*}{ E5 } & Initial & 2543 & 2562 & 3937 & $1 \mathrm{E}+10$ & $1 \mathrm{E}+06$ \\
& Optimal & 2005 & 2111 & 3083 & $2 \mathrm{E}+07$ & $1 \mathrm{E}+00$ \\
\hline \multirow{2}{*}{ E6 } & Initial & 5720 & 5749 & 6473 & $1 \mathrm{E}+10$ & $1 \mathrm{E}+06$ \\
& Optimal & 4460 & 4250 & 5496 & $1 \mathrm{E}+07$ & $1 \mathrm{E}+00$ \\
\hline \multirow{2}{*}{ E7 } & Initial & 2597 & 2602 & 3839 & $1 \mathrm{E}+10$ & $1 \mathrm{E}+06$ \\
& Optimal & 1996 & 2098 & 2792 & $2 \mathrm{E}+07$ & $1 \mathrm{E}+00$ \\
\hline \multirow{2}{*}{ E8 } & Initial & 3939 & 3919 & 5012 & $1 \mathrm{E}+10$ & $1 \mathrm{E}+06$ \\
& Optimal & 3086 & 2939 & 4200 & $2 \mathrm{E}+07$ & $1 \mathrm{E}+00$ \\
\hline \hline
\end{tabular}

\section{A.2.4 Radial Min}

Table 13: Settling Times and Respective $Q \& R$ for each Equilibrium Point at Radial Min-2\%

Position (s) Velocity (s) Euler Angles (s)

\begin{tabular}{lllllll}
\hline \hline $\mathbf{E} 1$ & Initial & 3052 & 3014 & 5385 & $1 \mathrm{E}+10$ & $1 \mathrm{E}+06$ \\
& Optimal & 2200 & 2082 & 4387 & $3 \mathrm{E}+09$ & $1 \mathrm{E}+00$ \\
\hline \multirow{2}{*}{ E2 } & Initial & 4814 & 4822 & 7327 & $1 \mathrm{E}+10$ & $1 \mathrm{E}+06$ \\
& Optimal & 2905 & 2707 & 5800 & $2 \mathrm{E}+09$ & $1 \mathrm{E}+00$ \\
\hline \multirow{2}{*}{$\mathbf{E 3}$} & Initial & 2860 & 2865 & 4929 & $1 \mathrm{E}+10$ & $1 \mathrm{E}+06$ \\
& Optimal & 2101 & 1984 & 3578 & $5 \mathrm{E}+08$ & $1 \mathrm{E}+00$ \\
\hline \multirow{2}{*}{$\mathbf{E 4}$} & Initial & 3189 & 2651 & 5996 & $1 \mathrm{E}+10$ & $1 \mathrm{E}+06$ \\
& Optimal & 2575 & 2142 & 4532 & $1 \mathrm{E}+09$ & $1 \mathrm{E}+00$ \\
\hline \multirow{2}{*}{$\mathbf{E 5}$} & Initial & 3121 & 3331 & 3968 & $1 \mathrm{E}+10$ & $1 \mathrm{E}+06$ \\
& Optimal & 4066 & 4028 & 3019 & $2 \mathrm{E}+10$ & $1 \mathrm{E}+00$ \\
\hline \multirow{2}{*}{ E6 } & Initial & 5684 & 5785 & 8150 & $1 \mathrm{E}+10$ & $1 \mathrm{E}+06$ \\
& Optimal & 3834 & 3981 & 7521 & $7 \mathrm{E}+08$ & $1 \mathrm{E}+00$ \\
\hline \multirow{2}{*}{$\mathbf{E 7}$} & Initial & 2326 & 2322 & 5267 & $1 \mathrm{E}+10$ & $1 \mathrm{E}+06$ \\
& Optimal & 3668 & 3820 & 3689 & $1 \mathrm{E}+11$ & $1 \mathrm{E}+00$ \\
\hline \multirow{2}{*}{ E8 } & Initial & 3078 & 3017 & 5187 & $1 \mathrm{E}+10$ & $1 \mathrm{E}+06$ \\
& Optimal & 2130 & 2088 & 3725 & $7 \mathrm{E}+09$ & $1 \mathrm{E}+00$ \\
\hline \hline
\end{tabular}




\section{A.2.5 Out of Plane Max}

Table 14: Settling Times and Respective $Q \& R$ for each Equilibrium Point at Out of Plane Max-2\%

\begin{tabular}{clccccc} 
& & Position $(\mathbf{s})$ & Velocity $(\mathbf{s})$ & Euler Angles $(\mathbf{s})$ & Q & R \\
\hline \hline \multirow{2}{*}{ E1 } & Initial & 2699 & 2888 & 5222 & $1 \mathrm{E}+10$ & $1 \mathrm{E}+06$ \\
& Optimal & 2296 & 2336 & 4152 & $4 \mathrm{E}+07$ & $1 \mathrm{E}+00$ \\
\hline \multirow{2}{*}{ E2 } & Initial & 4756 & 4765 & 5918 & $1 \mathrm{E}+10$ & $1 \mathrm{E}+06$ \\
& Optimal & 2446 & 2390 & 4174 & $3 \mathrm{E}+08$ & $1 \mathrm{E}+00$ \\
\hline \multirow{2}{*}{ E3 } & Initial & 2858 & 2849 & 5015 & $1 \mathrm{E}+10$ & $1 \mathrm{E}+06$ \\
& Optimal & 1837 & 1347 & 3032 & $2 \mathrm{E}+09$ & $1 \mathrm{E}+00$ \\
\hline \multirow{2}{*}{ E4 } & Initial & 4532 & 4530 & 6104 & $1 \mathrm{E}+10$ & $1 \mathrm{E}+06$ \\
& Optimal & 2866 & 2655 & 4172 & $1 \mathrm{E}+08$ & $1 \mathrm{E}+00$ \\
\hline \multirow{2}{*}{ E5 } & Initial & 2865 & 2907 & 4308 & $1 \mathrm{E}+10$ & $1 \mathrm{E}+06$ \\
& Optimal & 1997 & 2089 & 3361 & $5 \mathrm{E}+07$ & $1 \mathrm{E}+00$ \\
\hline \multirow{2}{*}{ E6 } & Initial & 6595 & 6577 & 7974 & $1 \mathrm{E}+10$ & $1 \mathrm{E}+06$ \\
& Optimal & 3646 & 3596 & 5956 & $1 \mathrm{E}+08$ & $1 \mathrm{E}+00$ \\
\hline \multirow{2}{*}{ E7 } & Initial & 2776 & 2785 & 4230 & $1 \mathrm{E}+10$ & $1 \mathrm{E}+06$ \\
& Optimal & 2032 & 1822 & 3271 & $6 \mathrm{E}+07$ & $1 \mathrm{E}+00$ \\
\hline \multirow{2}{*}{ E8 } & Initial & 3546 & 3489 & 4608 & $1 \mathrm{E}+10$ & $1 \mathrm{E}+06$ \\
& Optimal & 1397 & 1371 & 3315 & $5 \mathrm{E}+08$ & $1 \mathrm{E}+00$ \\
\hline \hline
\end{tabular}

\section{A.2.6 Out of Plane Min}

Table 15: Settling Times and Respective $Q \& R$ for each Equilibrium Point at Out of Plane Min-2\%

\begin{tabular}{clccccc} 
& & Position (s) & Velocity (s) & Euler Angles (s) & Q & R \\
\hline \hline E1 & Initial & 2699 & 2888 & 5148 & $1 \mathrm{E}+10$ & $1 \mathrm{E}+06$ \\
& Optimal & 1908 & 1438 & 3190 & $3 \mathrm{E}+09$ & $1 \mathrm{E}+00$ \\
\hline \multirow{2}{*}{ E2 } & Initial & 4756 & 4765 & 6282 & $1 \mathrm{E}+10$ & $1 \mathrm{E}+06$ \\
& Optimal & 4568213 & 2390 & 4316 & $3 \mathrm{E}+08$ & $1 \mathrm{E}+00$ \\
\hline \multirow{2}{*}{ E3 } & Initial & 2858 & 2849 & 4520 & $1 \mathrm{E}+10$ & $1 \mathrm{E}+06$ \\
& Optimal & 1575 & 1025 & 2869 & $4 \mathrm{E}+10$ & $1 \mathrm{E}+00$ \\
\hline \multirow{2}{*}{ E4 } & Initial & 4532 & 4530 & 6377 & $1 \mathrm{E}+10$ & $1 \mathrm{E}+06$ \\
& Optimal & 2250 & 1771 & 3789 & $2 \mathrm{E}+09$ & $1 \mathrm{E}+00$ \\
\hline \multirow{2}{*}{ E5 } & Initial & 2865 & 2907 & 4437 & $1 \mathrm{E}+10$ & $1 \mathrm{E}+06$ \\
& Optimal & 1218 & 1181 & 2485 & $1 \mathrm{E}+10$ & $1 \mathrm{E}+00$ \\
\hline \multirow{2}{*}{ E6 } & Initial & 6587 & 6568 & 8351 & $1 \mathrm{E}+10$ & $1 \mathrm{E}+06$ \\
& Optimal & 3346 & 3215 & 5982 & $2 \mathrm{E}+08$ & $1 \mathrm{E}+00$ \\
\hline \multirow{2}{*}{ E7 } & Initial & 2776 & 2785 & 4361 & $1 \mathrm{E}+10$ & $1 \mathrm{E}+06$ \\
& Optimal & 1965 & 1938 & 3163 & $1 \mathrm{E}+08$ & $1 \mathrm{E}+00$ \\
\hline \multirow{2}{*}{ E8 } & Initial & 3546 & 3489 & 5218 & $1 \mathrm{E}+10$ & $1 \mathrm{E}+06$ \\
& Optimal & 1278 & 1207 & 2994 & $1 \mathrm{E}+09$ & $1 \mathrm{E}+00$ \\
\hline \hline
\end{tabular}




\section{A.3 5\% Perturbation}

\section{A.3.1 In Plane Max}

Table 16: Settling Times and Respective $Q \& R$ for each Equilibrium Point at In Plane Max - 5\%

\begin{tabular}{clccccc} 
& & Position (s) & Velocity (s) & Euler Angles (s) & Q & R \\
\hline \hline \multirow{2}{*}{ E1 } & Initial & 3367 & 3392 & 4134 & $1 \mathrm{E}+10$ & $1 \mathrm{E}+06$ \\
& Optimal & 2417 & 2534 & 3688 & $2 \mathrm{E}+07$ & $1 \mathrm{E}+00$ \\
\hline \multirow{2}{*}{ E2 } & Initial & 4115 & 4303 & 5174 & $1 \mathrm{E}+10$ & $1 \mathrm{E}+06$ \\
& Optimal & 2976 & 3155 & 4816 & $1 \mathrm{E}+07$ & $1 \mathrm{E}+00$ \\
\hline \multirow{2}{*}{ E3 } & Initial & 2618 & 2729 & 3778 & $1 \mathrm{E}+10$ & $1 \mathrm{E}+06$ \\
& Optimal & 1886 & 2042 & 3036 & $2 \mathrm{E}+07$ & $1 \mathrm{E}+00$ \\
\hline \multirow{2}{*}{$\mathbf{E 4}$} & Initial & 3114 & 3322 & 4093 & $1 \mathrm{E}+10$ & $1 \mathrm{E}+06$ \\
& Optimal & 1952 & 2023 & 3394 & $1 \mathrm{E}+08$ & $1 \mathrm{E}+00$ \\
\hline \multirow{2}{*}{ E5 } & Initial & 2242 & 2630 & 3008 & $1 \mathrm{E}+10$ & $1 \mathrm{E}+06$ \\
& Optimal & 1897 & 2215 & 2333 & $1 \mathrm{E}+07$ & $1 \mathrm{E}+00$ \\
\hline \multirow{2}{*}{ E6 } & Initial & 4710 & 5153 & 5736 & $1 \mathrm{E}+10$ & $1 \mathrm{E}+06$ \\
& Optimal & 4829 & 4708 & 5559 & $1 \mathrm{E}+07$ & $1 \mathrm{E}+00$ \\
\hline \multirow{2}{*}{ E7 } & Initial & 2389 & 2716 & 3286 & $1 \mathrm{E}+10$ & $1 \mathrm{E}+06$ \\
& Optimal & 1950 & 2227 & 2607 & $9 \mathrm{E}+06$ & $1 \mathrm{E}+00$ \\
\hline \multirow{2}{*}{ E8 } & Initial & 2389 & 2715 & 3277 & $1 \mathrm{E}+10$ & $1 \mathrm{E}+06$ \\
& Optimal & 1949 & 2227 & 2598 & $9 \mathrm{E}+06$ & $1 \mathrm{E}+00$ \\
\hline \hline
\end{tabular}

\section{A.3.2 In Plane Min}

Table 17: Settling Times and Respective $Q \& R$ for each Equilibrium Point at In Plane Min-5\%

\begin{tabular}{clrcccc} 
& & Position (s) & Velocity (s) & Euler Angles (s) & Q & R \\
\hline \hline \multirow{2}{*}{ E1 } & Initial & 3367 & 3392 & 4325 & $1 \mathrm{E}+10$ & $1 \mathrm{E}+06$ \\
& Optimal & 2417 & 2534 & 3818 & $2 \mathrm{E}+07$ & $1 \mathrm{E}+00$ \\
\hline \multirow{2}{*}{ E2 } & Initial & 4115 & 4303 & 5366 & $1 \mathrm{E}+10$ & $1 \mathrm{E}+06$ \\
& Optimal & 2976 & 3155 & 4875 & $1 \mathrm{E}+07$ & $1 \mathrm{E}+00$ \\
\hline \multirow{2}{*}{ E3 } & Initial & 2618 & 2729 & 4017 & $1 \mathrm{E}+10$ & $1 \mathrm{E}+06$ \\
& Optimal & 2118 & 2266 & 3024 & $1 \mathrm{E}+07$ & $1 \mathrm{E}+00$ \\
\hline \multirow{2}{*}{$\mathbf{E 4}$} & Initial & 3115 & 3322 & 4330 & $1 \mathrm{E}+10$ & $1 \mathrm{E}+06$ \\
& Optimal & 2090 & 2347 & 3580 & $2 \mathrm{E}+07$ & $1 \mathrm{E}+00$ \\
\hline \multirow{2}{*}{ E5 } & Initial & 2242 & 2630 & 3168 & $1 \mathrm{E}+10$ & $1 \mathrm{E}+06$ \\
& Optimal & 1798 & 2040 & 2622 & $2 \mathrm{E}+07$ & $1 \mathrm{E}+00$ \\
\hline \multirow{2}{*}{ E6 } & Initial & 4736 & 5212 & 5910 & $1 \mathrm{E}+10$ & $1 \mathrm{E}+06$ \\
& Optimal & 4701 & 4537 & 5100 & $2 \mathrm{E}+07$ & $1 \mathrm{E}+00$ \\
\hline \multirow{2}{*}{ E7 } & Initial & 2389 & 2716 & 1352 & $1 \mathrm{E}+10$ & $1 \mathrm{E}+06$ \\
& Optimal & 1922 & 2192 & 1056 & $1 \mathrm{E}+07$ & $1 \mathrm{E}+00$ \\
\hline \multirow{2}{*}{ E8 } & Initial & 2389 & 2715 & 1348 & $1 \mathrm{E}+10$ & $1 \mathrm{E}+06$ \\
& Optimal & 2060 & 1748 & 2039 & $3 \mathrm{E}+07$ & $1 \mathrm{E}+00$ \\
\hline \hline
\end{tabular}




\section{A.3.3 Radial Max}

Table 18: Settling Times and Respective $Q \& R$ for each Equilibrium Point at Radial Max-5\%

\begin{tabular}{clrcccc} 
& & Position $(\mathbf{s})$ & Velocity $(\mathbf{s})$ & Euler Angles (s) & Q & R \\
\hline \hline E1 & Initial & 3544 & 3545 & 5392 & $1 \mathrm{E}+10$ & $1 \mathrm{E}+06$ \\
& Optimal & 2974 & 3060 & 4247 & $1 \mathrm{E}+07$ & $1 \mathrm{E}+00$ \\
\hline \multirow{2}{*}{ E2 } & Initial & 4524 & 4501 & 6378 & $1 \mathrm{E}+10$ & $1 \mathrm{E}+06$ \\
& Optimal & 3332 & 3441 & 5084 & $1 \mathrm{E}+07$ & $1 \mathrm{E}+00$ \\
\hline \multirow{2}{*}{ E3 } & Initial & 2928 & 3057 & 4996 & $1 \mathrm{E}+10$ & $1 \mathrm{E}+06$ \\
& Optimal & 2602 & 2603 & 4218 & $1 \mathrm{E}+07$ & $1 \mathrm{E}+00$ \\
\hline \multirow{2}{*}{$\mathbf{E 4}$} & Initial & 4015 & 4034 & 6215 & $1 \mathrm{E}+10$ & $1 \mathrm{E}+06$ \\
& Optimal & 2926 & 3035 & 4807 & $2 \mathrm{E}+07$ & $1 \mathrm{E}+00$ \\
\hline \multirow{2}{*}{ E5 } & Initial & 2543 & 2562 & 4359 & $1 \mathrm{E}+10$ & $1 \mathrm{E}+06$ \\
& Optimal & 2209 & 2285 & 3652 & $1 \mathrm{E}+07$ & $1 \mathrm{E}+00$ \\
\hline \multirow{2}{*}{ E6 } & Initial & 4757 & 5797 & 7098 & $1 \mathrm{E}+10$ & $1 \mathrm{E}+06$ \\
& Optimal & 4460 & 4250 & 6230 & $1 \mathrm{E}+07$ & $1 \mathrm{E}+00$ \\
\hline \multirow{2}{*}{ E7 } & Initial & 2597 & 2602 & 4307 & $1 \mathrm{E}+10$ & $1 \mathrm{E}+06$ \\
& Optimal & 2223 & 2290 & 3182 & $1 \mathrm{E}+07$ & $1 \mathrm{E}+00$ \\
\hline \multirow{2}{*}{ E8 } & Initial & 3939 & 3919 & 5578 & $1 \mathrm{E}+10$ & $1 \mathrm{E}+06$ \\
& Optimal & 3146 & 3236 & 4948 & $1 \mathrm{E}+07$ & $1 \mathrm{E}+00$ \\
\hline \hline
\end{tabular}

\section{A.3.4 Radial Min}

Table 19: Settling Times and Respective $Q \& R$ for each Equilibrium Point at Radial Min $-5 \%$

\begin{tabular}{|c|c|c|c|c|c|c|}
\hline & & Position (s) & Velocity (s) & Euler Angles (s) & $\mathbf{Q}$ & $\mathbf{R}$ \\
\hline \multirow{2}{*}{ E1 } & Initial & 3052 & 3015 & 5858 & $1 \mathrm{E}+10$ & $1 \mathrm{E}+06$ \\
\hline & Optimal & 2200 & 2082 & 4887 & $3 E+09$ & $1 \mathrm{E}+00$ \\
\hline \multirow[t]{2}{*}{ E2 } & Initial & 4813 & 4821 & 7706 & $1 \mathrm{E}+10$ & $1 \mathrm{E}+06$ \\
\hline & Optimal & 2906 & 2707 & 6307 & $2 \mathrm{E}+09$ & $1 \mathrm{E}+00$ \\
\hline \multirow[t]{2}{*}{ E3 } & Initial & 2860 & 2865 & 5251 & $1 \mathrm{E}+10$ & $1 \mathrm{E}+06$ \\
\hline & Optimal & 2146 & 2023 & 3946 & $4 \mathrm{E}+08$ & $1 \mathrm{E}+00$ \\
\hline \multirow[t]{2}{*}{ E4 } & Initial & 3189 & 2651 & 6648 & $1 \mathrm{E}+10$ & $1 \mathrm{E}+06$ \\
\hline & Optimal & 2658 & 2204 & 5036 & $6 \mathrm{E}+08$ & $1 \mathrm{E}+00$ \\
\hline \multirow[t]{2}{*}{ E5 } & Initial & 2424 & 2351 & 4196 & $1 \mathrm{E}+10$ & $1 \mathrm{E}+06$ \\
\hline & Optimal & 4425 & 4299 & 3543 & $1 \mathrm{E}+10$ & $1 \mathrm{E}+00$ \\
\hline \multirow[t]{2}{*}{ E6 } & Initial & 5684 & 5784 & 8860 & $1 \mathrm{E}+10$ & $1 \mathrm{E}+06$ \\
\hline & Optimal & 3719 & 3868 & 8072 & $9 \mathrm{E}+08$ & $1 \mathrm{E}+00$ \\
\hline \multirow[t]{2}{*}{ E7 } & Initial & 2326 & 2323 & 5575 & $1 \mathrm{E}+10$ & $1 \mathrm{E}+06$ \\
\hline & Optimal & 3806 & 3722 & 4155 & $1 \mathrm{E}+11$ & $1 \mathrm{E}+00$ \\
\hline \multirow[t]{2}{*}{ E8 } & Initial & 3078 & 3017 & 5525 & $1 \mathrm{E}+10$ & $1 \mathrm{E}+06$ \\
\hline & Optimal & 2289 & 2219 & 4439 & $4 \mathrm{E}+09$ & $1 \mathrm{E}+00$ \\
\hline
\end{tabular}




\section{A.3.5 Out of Plane Max}

Table 20: Settling Times and Respective $Q \& R$ for each Equilibrium Point at Out of Plane Max-5\%

\begin{tabular}{clccccc} 
& & Position (s) & Velocity (s) & Euler Angles (s) & Q & R \\
\hline \hline \multirow{2}{*}{ E1 } & Initial & 2699 & 2888 & 5567 & $1 \mathrm{E}+10$ & $1 \mathrm{E}+06$ \\
& Optimal & 2362 & 2404 & 4528 & $3 \mathrm{E}+07$ & $1 \mathrm{E}+00$ \\
\hline \multirow{2}{*}{ E2 } & Initial & 4759 & 4769 & 6369 & $1 \mathrm{E}+10$ & $1 \mathrm{E}+06$ \\
& Optimal & 2833 & 2856 & 4920 & $1 \mathrm{E}+08$ & $1 \mathrm{E}+00$ \\
\hline \multirow{2}{*}{ E3 } & Initial & 2858 & 2849 & 5254 & $1 \mathrm{E}+10$ & $1 \mathrm{E}+06$ \\
& Optimal & 2207 & 2007 & 3838 & $1 \mathrm{E}+08$ & $1 \mathrm{E}+00$ \\
\hline \multirow{2}{*}{ E4 } & Initial & 4533 & 4531 & 6497 & $1 \mathrm{E}+10$ & $1 \mathrm{E}+06$ \\
& Optimal & 2059 & 1532 & 4022 & $1 \mathrm{E}+10$ & $1 \mathrm{E}+00$ \\
\hline \multirow{2}{*}{ E5 } & Initial & 2865 & 2907 & 4578 & $1 \mathrm{E}+10$ & $1 \mathrm{E}+06$ \\
& Optimal & 2238 & 2291 & 3974 & $3 \mathrm{E}+07$ & $1 \mathrm{E}+00$ \\
\hline \multirow{2}{*}{ E6 } & Initial & 6595 & 6577 & 8495 & $1 \mathrm{E}+10$ & $1 \mathrm{E}+06$ \\
& Optimal & 3646 & 3596 & 6602 & $1 \mathrm{E}+08$ & $1 \mathrm{E}+00$ \\
\hline \multirow{2}{*}{ E7 } & Initial & 2776 & 2785 & 4501 & $1 \mathrm{E}+10$ & $1 \mathrm{E}+06$ \\
& Optimal & 1920 & 1996 & 3626 & $4 \mathrm{E}+07$ & $1 \mathrm{E}+00$ \\
\hline \multirow{2}{*}{ E8 } & Initial & 3546 & 3489 & 5020 & $1 \mathrm{E}+10$ & $1 \mathrm{E}+06$ \\
& Optimal & 1447 & 1431 & 3762 & $4 \mathrm{E}+08$ & $1 \mathrm{E}+00$ \\
\hline \hline
\end{tabular}

\section{A.3.6 Out of Plane Min}

Table 21: Settling Times and Respective $Q \& R$ for each Equilibrium Point at Out of Plane Min-5\%

\begin{tabular}{clrcccc} 
& & Position (s) & Velocity (s) & Euler Angles (s) & Q & R \\
\hline \hline E1 & Initial & 2699 & 2888 & 5557 & $1 \mathrm{E}+10$ & $1 \mathrm{E}+06$ \\
& Optimal & 1908 & 1772 & 3533 & $3 \mathrm{E}+09$ & $1 \mathrm{E}+00$ \\
\hline \multirow{2}{*}{ E2 } & Initial & 4758 & 4768 & 6700 & $1 \mathrm{E}+10$ & $1 \mathrm{E}+06$ \\
& Optimal & 2003 & 1470 & 4203 & $2 \mathrm{E}+10$ & $1 \mathrm{E}+00$ \\
\hline \multirow{2}{*}{ E3 } & Initial & 2858 & 2849 & 4898 & $1 \mathrm{E}+10$ & $1 \mathrm{E}+06$ \\
& Optimal & 1921 & 1454 & 3420 & $1 \mathrm{E}+09$ & $1 \mathrm{E}+00$ \\
\hline \multirow{2}{*}{ E4 } & Initial & 4533 & 4531 & 6763 & $1 \mathrm{E}+10$ & $1 \mathrm{E}+06$ \\
& Optimal & 2250 & 1771 & 4253 & $2 \mathrm{E}+09$ & $1 \mathrm{E}+00$ \\
\hline \multirow{2}{*}{ E5 } & Initial & 2865 & 2907 & 4725 & $1 \mathrm{E}+10$ & $1 \mathrm{E}+06$ \\
& Optimal & 1153 & 1023 & 2719 & $4 \mathrm{E}+10$ & $1 \mathrm{E}+00$ \\
\hline \multirow{2}{*}{ E6 } & Initial & 6595 & 6577 & 9012 & $1 \mathrm{E}+10$ & $1 \mathrm{E}+06$ \\
& Optimal & 3646 & 3596 & 6753 & $1 \mathrm{E}+08$ & $1 \mathrm{E}+00$ \\
\hline \multirow{2}{*}{ E7 } & Initial & 2776 & 2785 & 4647 & $1 \mathrm{E}+10$ & $1 \mathrm{E}+06$ \\
& Optimal & 1965 & 1938 & 3335 & $1 \mathrm{E}+08$ & $1 \mathrm{E}+00$ \\
\hline \multirow{2}{*}{ E8 } & Initial & 3546 & 3489 & 5600 & $1 \mathrm{E}+10$ & $1 \mathrm{E}+06$ \\
& Optimal & 2251 & 2213 & 3936 & $4 \mathrm{E}+07$ & $1 \mathrm{E}+00$ \\
\hline \hline
\end{tabular}

